\title{
Improving the CFD modeling of Cross-ventilation in Highly-packed Urban Areas
}

\author{
Mohammadreza Shirzadi $^{\text {a }}$, Parham A. Mirzaei ${ }^{\mathrm{b}, 1}$, Mohammad Naghashzadegan ${ }^{\mathrm{a}}$ \\ ${ }^{\text {a }}$ Engineering Department, University of Guilan, Rasht, Iran \\ ${ }^{\mathrm{b}}$ Architecture and Built Environment Department, University of Nottingham, Nottingham, UK
}

\begin{abstract}
Computational Fluid Dynamics (CFD) simulations are widely used in many wind-related studies, including cross-ventilation, in urban areas. The accuracy of the CFD models, however, is still a challenging issue for accurate prediction of the complex flow behavior around and inside the buildings. Application of sophisticated CFD models, such as Large Eddy Simulation (LES) and unsteady Reynolds averaged Navier-Stokes (RANS), are generally limited, so many researchers and designers utilize the steady RANS models for design and analysis of crossventilation performance in urban areas. The RANS models, however, provide poor results in predicting the cross-ventilation in street canyons.

Thus, this study aims to understand and quantify limitations of the steady RANS models for cross-ventilation applications in highly-packed urban areas. To this end, a series of CFD simulations were conducted for a group of buildings, which were arranged in regular and staggered orders with different urban area densities. Both sealed-body and cross-ventilated scenarios were considered in this study while the surface-averaged and local values of the wind pressure were compared with the results from a wind tunnel measurement by Tamura (2012).

Furthermore, the possibility of the RANS model improvement was considered using a parameter sensitivity study over the closure coefficients of a RANS model. Therefore, new coefficients for urban area with densities between 0.2 and 0.4 were found to significantly improve the accuracy of the RANS model. Nonetheless, as an interesting finding of this study, for higher values of urban area densities above 0.4, CFD results went outside the expected measurement ranges; this implies that CFD modeling of higher density urban areas should be treated with more cautious and further studies are required to develop a guideline for such applications.
\end{abstract}

Keywords: Urban morphology, cross-ventilation, CFD, wind pressure, accuracy

\section{Introduction}

The energy demand of building sector is about $20 \%$ of the total energy delivered worldwide while the projections depict an average rate increase of 1.5\%/year until 2040 (Sieminski 2015). Effective energy saving strategies are thus required to decrease such energy demand while

\footnotetext{
${ }^{1}$ Corresponding author: University Park, Nottingham, NG2RD, UK

Tel.: +44 011595 14129; fax: +44 01159513159

Email: Parham.Mirzaei Ahranjani@nottingham.ac.uk
} 
keeping the thermal comfort and air quality at an acceptable level in indoor and outdoor spaces. Natural ventilation, as an effective method, has been frequently used in traditional and modern buildings (Aydin and Mirzaei 2016). The wind-driven cross-ventilation, which is the most common form of the natural ventilation, has been extensively utilized for energy demand reduction in buildings (Geros, Santamouris et al. 2005), (Guo, Liu et al. 2015), (Mochida, Yoshino et al. 2006), pollution removal from street canyons (Yang, Gao et al. 2016), (Mirzaei and Haghighat 2011), and indoor thermal comfort studies (Mochida, Yoshino et al. 2005, Prakash and Ravikumar 2015). In the urban areas, however, due to the complexity of the urban morphology with the existence of numerous buildings and obstacles, more considerations are required to achieve and maximize the cross-ventilation potentials.

The complex turbulent flow around the buildings, which includes unsteady vortex shedding and recirculating flow, separation and reattachment of the boundary layer (Rodi 1997, Hirose, Hagishima et al. 2014), and large-scale fluctuations in velocity and turbulent kinetic energy (TKE) parameters (Tominaga 2015), in addition to existence of highly unsteady phenomena such as flapping jet and Kelvin-Helmholtz instabilities inside the cross-ventilated building (Tominaga and Blocken 2016), turn the cross-ventilation studies in urban areas to a challenging subject both from experimental and numerical points of view. Experimental study by Tominaga and Blocken (2015) showed an airflow reduction of about $30 \%$ when sheltered effects are considered. Numerical study by (Cheung and Liu 2011, Kasim, Zaki et al. 2014) also indicated the same trend and emphasized on the importance of considering the sheltering effects of surrounding buildings on the cross-ventilation performance.

Different methods are normally employed for performance prediction of the cross-ventilation in urban environments, including full-scale and wind tunnel measurements, computational fluid dynamics (CFD), and network-based simplified methods such as airflow network (AFN). Fullscale measurement (Katayama, Tsutsumi et al. 1992, Sawachi, Ken-ichi et al. 2004, Yang, Wright et al. 2006) provides valuable data for the cross-ventilation analysis of the real geometry of the buildings; however, its application is limited due to the high cost of the experimental apparatus and the incapability to control the environmental parameters such as wind speed, wind direction, turbulence level, sheltering condition, etc. Wind-tunnel measurement (Murakami 1991, Katayama, Tsutsumi et al. 1992, Karava 2008, Tominaga and Blocken 2016), on the other hand, offers extra capability to control the environmental parameters and is extensively utilized for simplified building geometries. Again, such studies are limited due to the cost and time limitations and complex calibration procedures of measurement apparatus that directly affect the measurement quality. Network-based simplified models (Walton and Dols 2006), which are based on Bernoulli's equation and the orifice model as an abridged forms of NavierStokes equations (Ohba, Kurabuchi et al. 2002, Ohba, Kurabuchi et al. 2004, Kurabuchi, Ohba et al. 2005, Kobayashi, Sagara et al. 2009), are extensively used for the cross-ventilation analysis (Asfour and Gadi 2007, Ramponi, Angelotti et al. 2014, Arendt, Krzaczek et al. 2017). The discharge coefficient $\left(C_{d}\right)$ and surface wind pressure coefficient $\left(C_{P}\right)$ are two important parameters within these models, which are obtained numerically or experimentally. There is a level of uncertainty in the value of the discharge coefficient as a constant value between 0.6 and 0.7 as usually assumed for $C_{d}$ whilst the real value varies noticeably as a function of the openings position (Kurabuchi, Ohba et al. 2005, Karava, Stathopoulos et al. 2011), wind angle 
(Sawachi, Ken-ichi et al. 2004), turbulence parameters (Chu, Chiu et al. 2009), and sheltered condition. The value of $C_{P}$ is available in the form of analytical correlations and look up tables (Sawachi, Ken-ichi et al. 2004, Handbook 2009), but as emphasized by (Costola, Blocken et al. 2009), there is a high level of uncertainty in the value of $C_{P}$ when sheltering effect is considered. This coefficient for sheltering scenarios can be obtained from different sources. For example, in (Handbook 2009) surface-averaged $C_{P}$ is given for simple rectangular buildings as a function of floor plan, aspect ratio and wind angle; the sheltering effects can be then calculated based on a correlation factor for the reference wind speed, but with a high level of uncertainty.

CFD models, as an alternative and extensively utilized approach, are cheaper than the full-scale and wind tunnel measurements while more accurate than the network-based simplified models (Akamine, Kurabuchi et al. 2004, Hu, Ohba et al. 2008, Cheung and Liu 2011, Ramponi and Blocken 2012). However, the accuracy of the CFD simulations for the flow analysis in urban areas is limited due to the poor accuracy of the steady RANS (Reynolds averaged NavierStokes) turbulence models for prediction of momentum diffusion inside the street canyon and around the buildings (Tominaga 2015). More accurate CFD simulations, including LES (Hu, Ohba et al. 2008, Tong, Chen et al. 2016, van Hooff, Blocken et al. 2016) and unsteady RANS (Hua, Ohbab et al. 2006, Stavridou and Prinos 2017), are more reliable approaches to simulate the complex behavior of flow parameters around the buildings, but their inherent computational costs restrict their applications for realistic engineering problems in urban studies. Despite of many reports on the advantage of the LES over the RANS models, the uncertainty of the LES outputs is still noticeable for highly-packed environments. The calculated drag coefficient over a sheltered building model using LES by Razak, Hagishima et al. (2013) showed a relatively large deviation of about $45 \%$ compared with the results of another LES model by Kanda (2006) for urban area densities larger than 0.25 . Both models, however, depicted very similar results for urban area densities less than 0.25 in terms of velocity profiles and drag coefficients. In another LES work by Hirose, Hagishima et al. (2014), relative errors of about $35-50 \%$ compared to an experimental results by Zaki, Hagishima et al. (2012) were reported for the calculation of the surface pressure over a sheltered building with urban area density of 0.25 .

Despite many modifications performed on the RANS turbulence models, e.g. $R N G k-\varepsilon$ (Yakhot and Orszag 1986), and Realizable $k-\varepsilon$ (Shih, Liou et al. 1995, Younis and Zhou 2006), their application for the atmospheric boundary layer (ABL) flow modeling is still a challenging issue (Lateb, Meroney et al. 2016). As an example, a velocity prediction error of about $42 \%$ was obtained for RANS simulations of a sheltered building model with urban area density of 0.25 (Kasim, Zaki et al. 2016). In another work by (Ramponi 2015), the standard $k-\varepsilon$ model was used to calculate the wind surface pressure over the windward surface of a sheltered building with different heights and area densities; the reported error for the wind surface pressure over the windward opening for area densities of 0.3 and 0.6 were respectively found to be $26 \%$ and $48 \%$ for a building height of $12 \mathrm{~m}$ and $34 \%$ and $96 \%$ for a building height of $18 \mathrm{~m}$.

One of the main limitations of the RANS family turbulence models for such applications in highly-packed urban areas, as stated above, is related to the values of the closure coefficients. In general, the classical approach to find the closure coefficients is based on a few fundamental and classical flow regimes, which include homogenous decaying turbulence, free sheer flow, 
and fully developed channel flow. Nevertheless, none of these classical flows have noticeable similarities with the flow behavior in $A B L$ over the urban morphology. The default values of these parameters, for the standard $k-\varepsilon$ model as embedded in most CFD tools, such as ANSYS CFX, ANSYS FLUENT, PHOENIX, and STAR CCM+, are based on the work presented by Launder and Spalding (1974). These values are estimated in a way that makes the turbulence model applicable for different flow problems while keep the model accuracy in a reasonable range (Pope 2001). Experiments by Mohamed and LaRue (1990) showed that a value of 1.77 would be a more suitable one for $C_{\varepsilon 2}$ while the default value is 1.92 . The variation of $C_{\mu}$ in other studies by Kim, Moin et al. (1987) and Pope (2001) was reported to be between 0.06 and 0.095 , and 0.07 and 0.11 , respectively. Also, different values for $\frac{C_{\varepsilon 2}-1}{C_{\varepsilon 1}-1}$ were reported by Tavoularis and Karnik (1989), ranging from 1.33 to 1.75.

The aim of this study is to investigate the accuracy and assess the limitations of the steady RANS models for the cross-ventilation flow in urban areas as a function of the urban morphology. Furthermore, this paper fosters the possibility of improving these models with calibration of the closure coefficients for different urban area densities and building arrangements. To this end, a series of CFD simulations for a number of sealed-body (SB) and cross-ventilation (CV) scenarios are defined for an array of buildings with different urban area densities and arrangements. Then, the results are compared with an experimental data for sealed-body measurements by Tamura (2012). Modification of the RANS turbulent models is then discussed for accuracy improvement of CFD modeling of airflow behavior in highly-packed urban areas.

\section{METHODOLOGY}

\subsection{Procedure Description}

In Figure 1, a schematic of the proposed methodology for investigation of the accuracy of CFD models for the cross-ventilation modeling in urban areas is shown. In the first step, a CFD validation study was conducted for an isolated building model with two openings on the opposite sides with a wall-porosity of about $10 \%$. The validation study was conducted by comparing the passing airflow rate, velocity and TKE distributions inside the building with those obtained experimentally by Tominaga and Blocken (2015). In the next step, a series of CFD simulations for an array of low-rise generic buildings were conducted for different urban area densities $\left(C_{A}\right)$, ranging from 0.0 to 0.6 . The urban area density is defined as the ratio of the area occupied by the buildings to the area of the site as expressed below (Tamura 2012):

$C_{A}=\frac{b d}{B D}$

where $B$ and $D$ are the average distances between corresponding points on the adjacent buildings while $b$ and $d$ are the breadth and depth of the buildings (see Figure 2a). For each urban area density, two different scenarios were considered, including a sealed-body model and a cross-ventilated model. The dimensions of the building models for sealed-body and crossventilated models are shown in Figure $2 \mathrm{~b}$ and Figure $2 \mathrm{c}$, respectively. The size of the target building and surrounding buildings are the same for both models with dimensions $B \times D \times H=$ 
$0.16 m \times 0.24 m \times 0.12 m$. The dimensions of the windward and leeward openings in the crossventilated models are the same with $w=0.074 \mathrm{~m}$ and $L=0.026 \mathrm{~m}$.

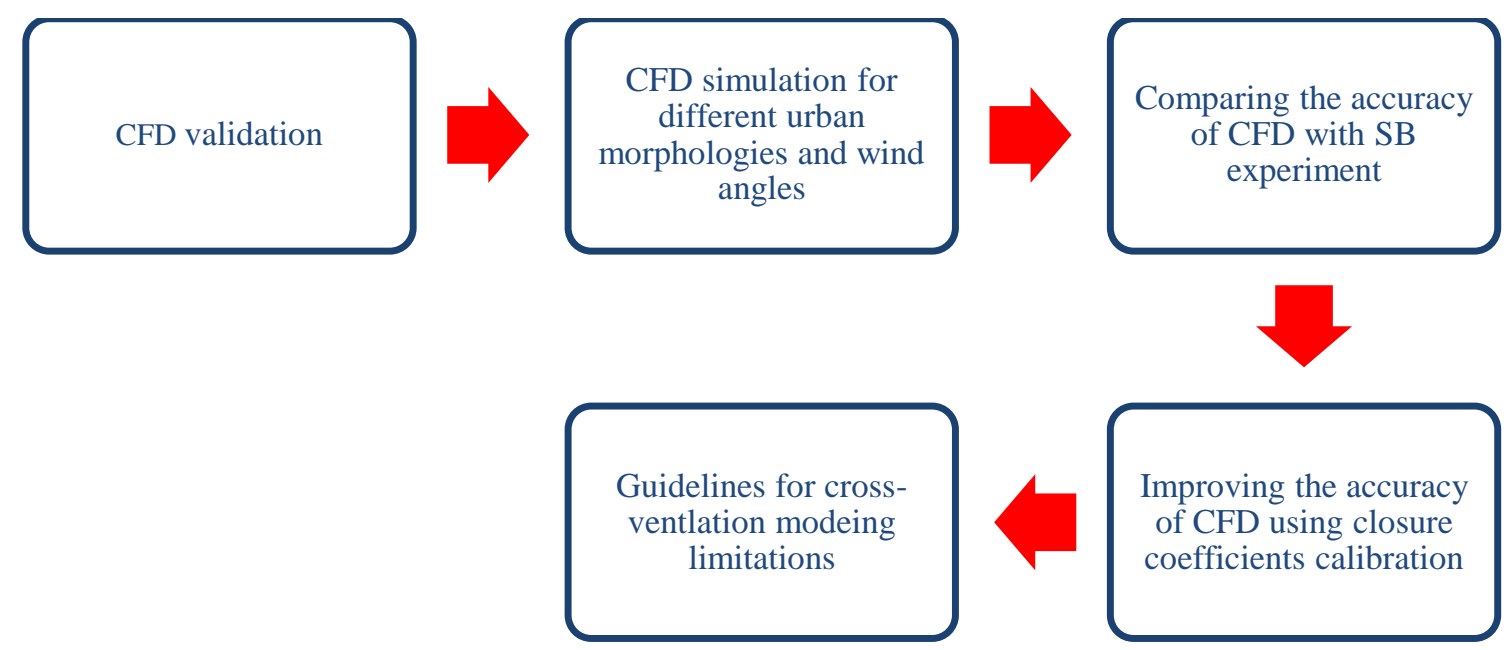

Figure 1 A schematic of the proposed methodology

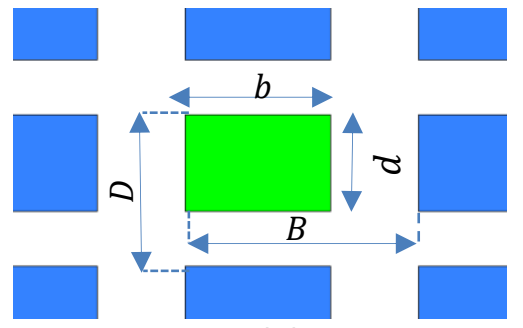

(a)

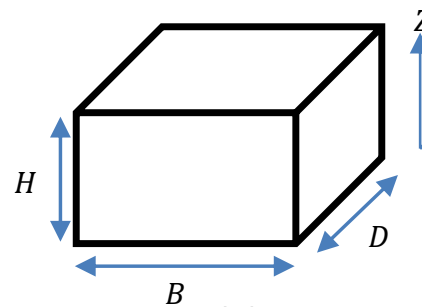

(b)

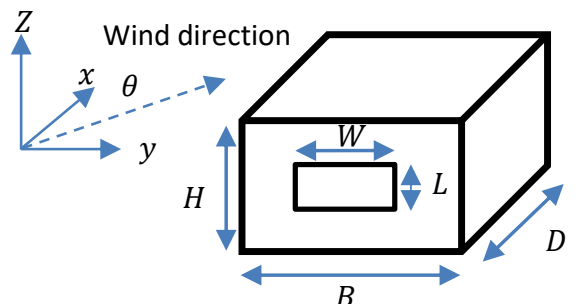

(c)

Figure 2 (a) Urban area density definition parameters, (b) sealed-body model dimensions, (c) cross-ventilated model dimensions

Moreover, two different urban morphologies were considered in this study, including the regular and staggered arrangements for both sealed-body and cross-ventilated scenarios (see Figure 3). Numbers of the surrounding buildings are also depicted in Figure 3 for each urban area density. Five different wind angles varying from $0^{\circ}$ to $90^{\circ}$ were also considered for all scenarios.

Next step comprises of a systematic comparison between the CFD results and the experimental data by Tamura (2012) in terms of wind surface pressure over the windward and leeward facades. The values of the surface-averaged wind pressure difference $\left(\Delta C_{P}\right)$ over the windward and leeward facades were calculated as follows:

$\Delta C_{P}=C_{P}^{\text {windward }}-C_{P}^{\text {leeward }}$

where $C_{P}^{\text {windward }}$ and $C_{P}^{\text {leeward }}$ are the surface-averaged wind pressure coefficients over the windward and leeward facades, respectively. The value of $\Delta C_{P}$ was calculated for both sealedbody and cross-ventilated building models. For the cross-ventilated building models, the value of the crossing airflow rate was calculated as below: 
dimensionless airflow rate $=\frac{Q}{U_{H} A_{\text {in }}}$

where $Q$ is the volumetric airflow rate through the cross-ventilated building. $U_{H}$ and $A_{\text {in }}$ are respectively the stramwise velocity at the building height and area of the inlet opening $(w \times L)$. Using the comparison study, limitations of the RANS models are discussed and possible modifications of the closure coefficients of the RANS models to improve the accuracy of the cross-ventilation modeling in urban areas are explored.

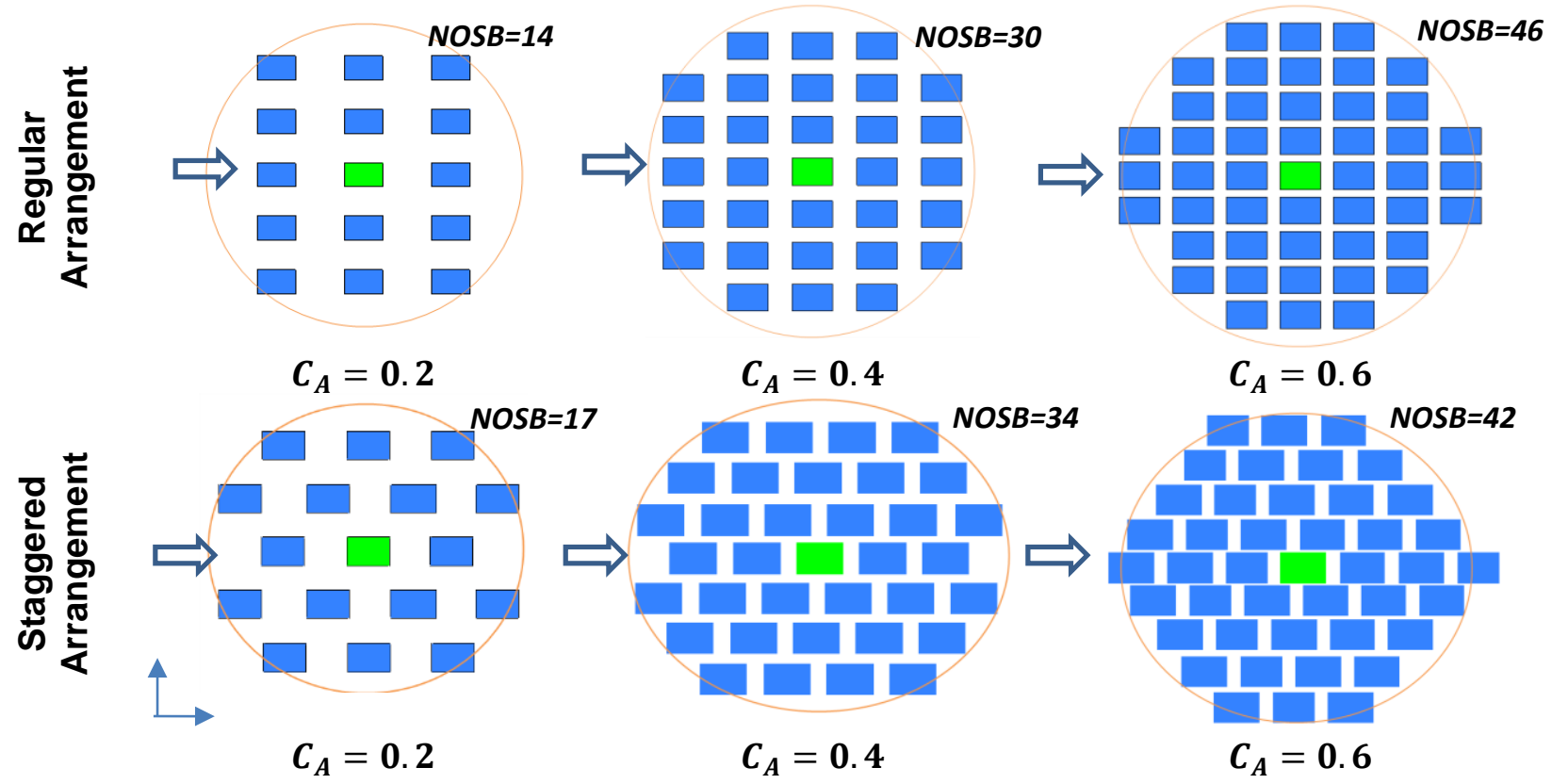

Figure 3 Different urban area densities of surrounding buildings in regular and staggered arrangements and number of the surrounding buildings (NOSB)

\subsection{Experimental Setup for the Sealed-body Wind Surface Pressure Coefficient}

The local distribution of the wind surface pressure coefficient $\left(c_{P}\right)$ was adapted from the measurements conducted by Tamura (2012) in which wall pressure distributions over a flat-, gable-, and hip-roofed type of low-rise buildings were measured in a boundary layer wind tunnel. In this experiment, three kinds of building arrangements, including regular, staggered, and random morphologies were considered while effects of the buildings relative height, wind angle, and urban area density were investigated. The urban area density was varied from 0.0 to 0.6 while different relative heights $(H)$ of $60 \mathrm{~mm}, 120 \mathrm{~mm}$, and $180 \mathrm{~mm}$ were considered. Furthermore, a series of turbulence-generated spires, roughness elements, and a carpet were used to simulate the terrain category III of AlJ (Tamura, Ohkuma et al. 2004). The wind velocity and turbulence intensity at a height of $10 \mathrm{~cm}$ were measured to be $7.8 \mathrm{~m} / \mathrm{s}$ and 0.25 , respectively.

For the building model with dimensions of $0.16 m \times 0.24 m \times 0.12 m(B \times D \times H)$, a total number of 202 pressure taps were uniformly installed over the building surfaces and connected to a scavi-valve system via synthetic resin tubes with $1.2 \mathrm{~mm}$ internal diameter. The original wind pressure coefficient at each measurement points was calculated as below: 
$C_{P_{-} \text {ori }}(i, t)=\frac{P(i, t)}{0.5 \rho U_{H}^{2}}$

where $P(i, t)$ is the measured wind pressure at a pressure tap $i$ at time $t, \rho$ is the air density, and $U_{H}$ is the wind speed at a reference height of $H$. The time series of the pressure coefficients were obtained from the moving-average formulation as follows (Tamura 2012):

$C_{P}(i, t)=\overline{C_{P_{-} \text {orl }}\left(l, t-\frac{\Delta t}{2} \sim t+\frac{\Delta t}{2}\right)}$

where $\Delta t=0.0064 \mathrm{~s}$ is the moving-average duration time. Each building configuration was sampled 10 times and the mean values of the measured pressure coefficients were calculated as defined below:

$\overline{C_{P}(l)}=\frac{1}{10} \sum_{n=1}^{10} \overline{C_{p}^{n}(l, t)}$

where $\frac{n=1}{C_{p}^{n}(l, t)}$ is the mean value of the time series of the $n$th sample. In Figure $4 \mathrm{a}$, variation of the mean and extreme values of the surface wind pressure coefficient are shown for different wind angles in regular arrangement for $C_{A}=0.2$. The distribution of the mean value of the local pressure coefficient over the building surfaces for normal wind angle is also shown in Figure $4 \mathrm{~b}$ for $C_{A}=0.2$.

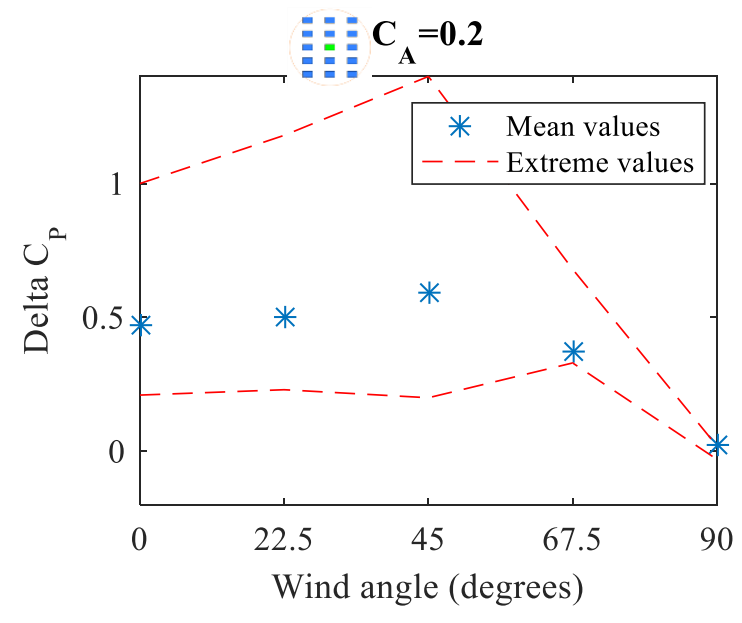

(a)

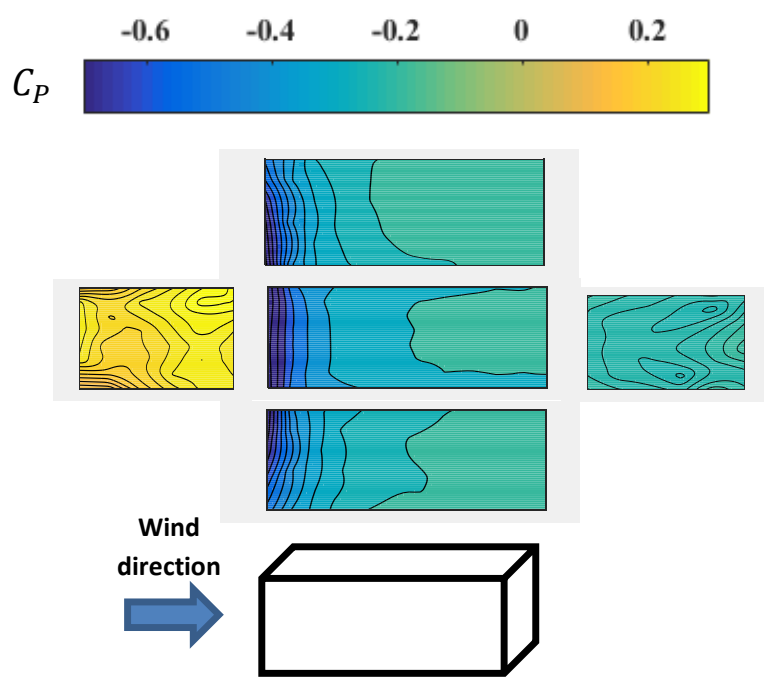

(b)

Figure 4 (a) Mean and extreme values of the surface-averaged wind surface pressure, and (b) mean wind surface pressure over the building surfaces for $C_{A}=0.2$ in regular arrangement

\subsection{Mathematical Modeling}

\subsubsection{CFD Model}

The 3D steady Reynolds averaged Navier-Stokes (RANS) equations were used to simulate the airflow around and inside the building model. The RANS equations can be derived by substituting mean and fluctuating components of the airflow variables into the Navier-Stokes equations (Richards and Norris 2011): 


$$
\begin{aligned}
& \frac{\partial\left(U_{j}\right)}{\partial x_{j}}=0 \\
& U_{j} \frac{\partial}{\partial x_{j}}\left(U_{i}\right)=-\frac{\partial P}{\partial x_{i}}+\frac{\partial}{\partial x_{j}}\left(\mu_{l}\left[\frac{\partial U_{i}}{\partial x_{j}}+\frac{\partial U_{j}}{\partial x_{i}}\right]-\rho \overline{u_{\imath} u_{J}}\right)
\end{aligned}
$$

where $U_{i}$ and $u_{i}$ are the average velocity and fluctuating velocity, respectively and $\mu_{l}$ is the molecular viscosity. Two different turbulence models, including the standard $k-\varepsilon$ and SST models, were used in the conducted CFD simulations.

\subsubsection{CFD Simulation Setup, Computational Domain and Boundary Conditions}

The RANS equations were solved using the commercial software ANSYS CFX and utilizing an element-based finite volume discretization method. The pressure-velocity coupling was based on the Rhie-Chow interpolation by Rhie and Chow (1983) while a co-located grid layout was further implemented. The High Resolution Scheme was used for discretization of the advection terms while tri-linear shape functions were used to evaluate the spatial derivatives of the diffusion terms. For the near-wall treatment, the automatic and scalable wall function formulations were adapted for $S S T$ and $k-\varepsilon$ models, respectively. The convergence criteria were set to be less than $10^{-5}$ for all variables.

A cylindrical computational domain, as shown in Figure 5a, was created for the CFD simulations based on the recommendations by Mirzaei and Carmeliet (2013) and AlJ guidelines (Tominaga, Mochida et al. 2008). Moreover, ICEM CFD was used to create a hexahedral mesh around and inside the building model. An O-grid block with first-layer size of $1 \times 10^{-4}(\mathrm{~m})$ was used for the solid walls, resulting in an average $\mathrm{y}^{+} \approx 1$. Number of cells for CFD calculations was determined by conducting a mesh sensitivity study for the regular building arrangement in $C_{A}=$ 0.2 . The numbers of cells for coarse, medium, and fine meshes were $2,047,656$ and $3,481,525$ and 5,916,245, respectively. The deviation between the results of the medium and fine meshes was less than $1.5 \%$ in prediction of the velocity profiles around the target building. Hence, the medium mesh configuration was selected for the simulations. By implementing the medium mesh configuration, the number of cells for sealed-body scenarios in urban area densities of 0 , 0.4 , and 0.6 , was then found to be 831,231 and $6,378,356$ and 9,202,383, respectively. The cross-ventilation building models had an additional cell numbers of about 250,000 in comparison with the sealed-body models. A view of the computational grids for the regular and staggered arrangements is shown in Figure $5 \mathrm{~b}$ and Figure 5c. Also, the enlarged views of the mesh configuration around the sealed-body and cross-ventilation models are displayed in Figure $5 \mathrm{~d}$.

No-slip boundary condition was considered for all solid walls with aerodynamically smooth surfaces. The symmetric wall boundary condition was also applied to the top boundary, and a zero static pressure was assigned to the outlet boundary. The inlet streamwise velocity in addition to the TKE profiles were adapted from the experiment by Tamura (2012) (see Figure 6) to mock the condition at the lower part of a neutral atmospheric boundary layer (Richards and Hoxey 1993): 


$$
U(z)=\frac{U_{A B L}^{*}}{\kappa} \ln \left(\frac{z+z_{0}}{z_{0}}\right)
$$

where $U(z)$ is the streamwise velocity at the height of $z$ and $\kappa$ is the von Karman constant equals to $0.42 . z_{0}=2 \mathrm{~mm}$ is the aerodynamic roughness and $U_{A B L}^{*}$ is the friction velocity set to be $0.83 \mathrm{~m} / \mathrm{s}$. The vertical profile of the TKE was also approximated as below (Ramponi 2015):

$k(z)=(I(z) U(z))^{2}$

where $I(z)$ denotes the experimentally measured turbulence intensity. The turbulent kinetic energy dissipation rate was estimated as follows (Richards and Hoxey 1993):

$\varepsilon(z)=\frac{U_{A B L}^{*}{ }^{3}}{z_{0}}$

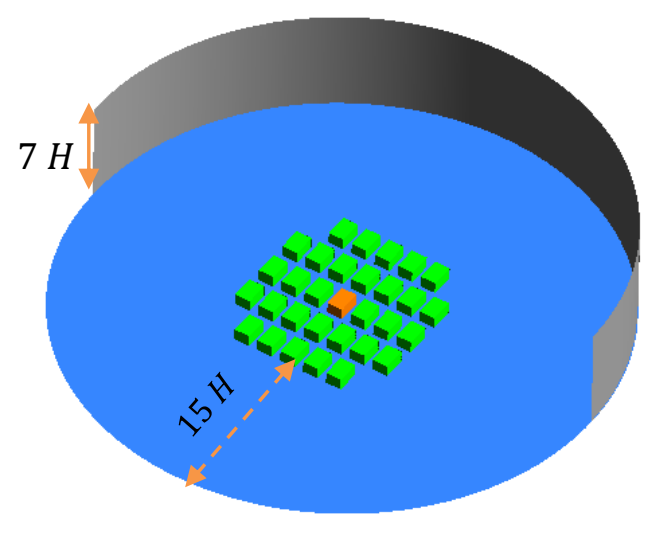

(a)

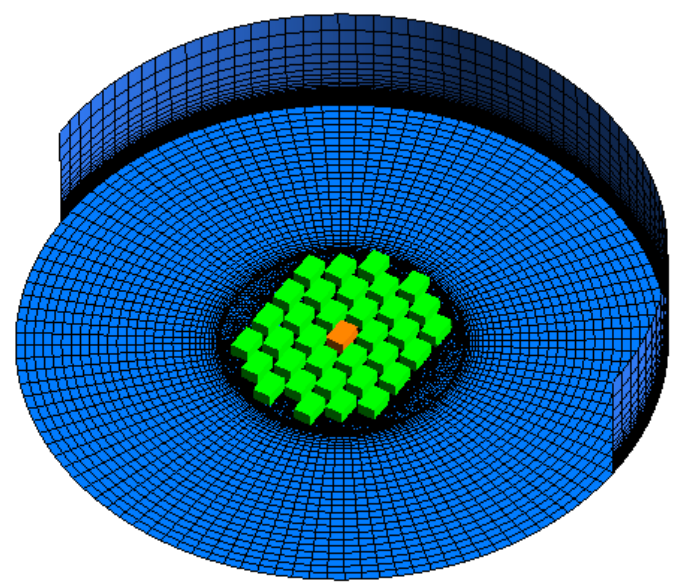

(c)

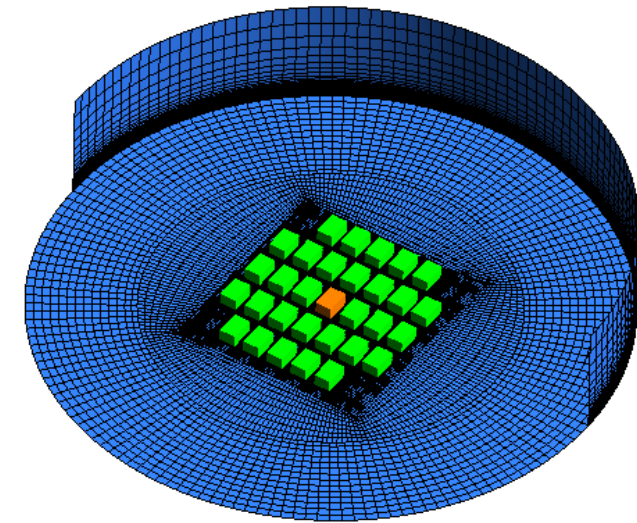

(b)

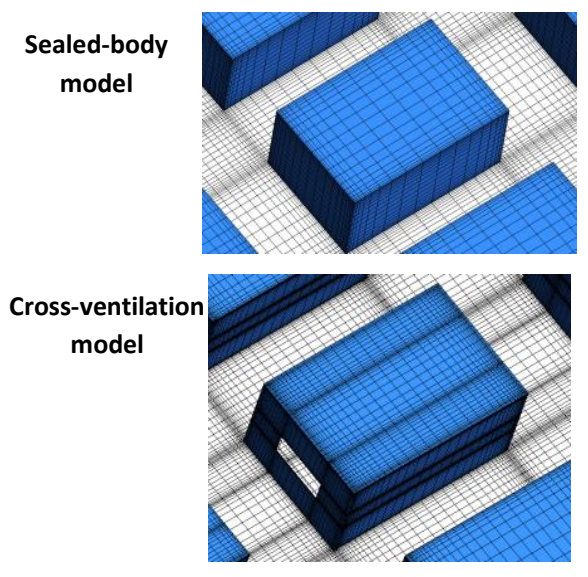

(d)

Figure 5 (a) Computational domain, computational grid for (b) regular, (c) staggered arrangements, and (d) sealed-body and cross-ventilation models 


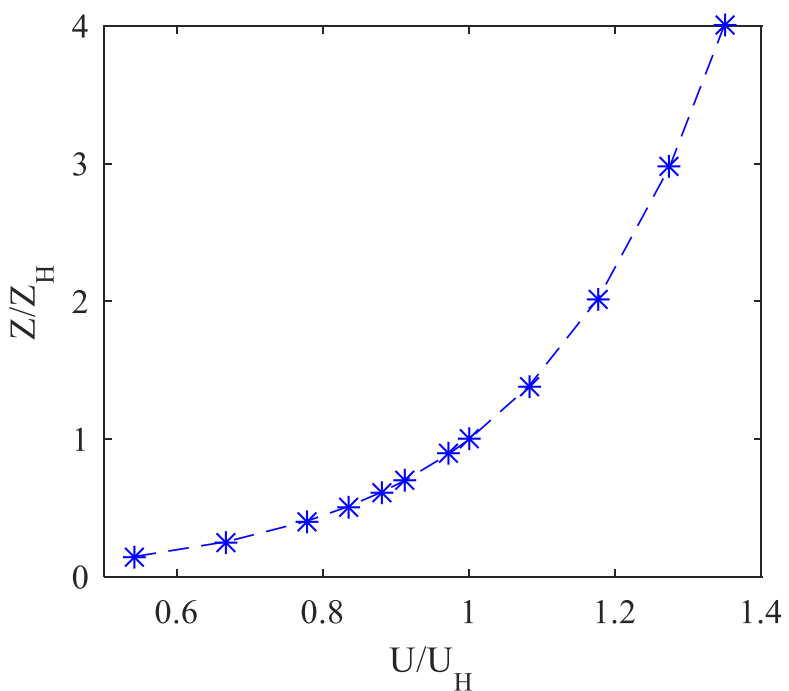

(a)

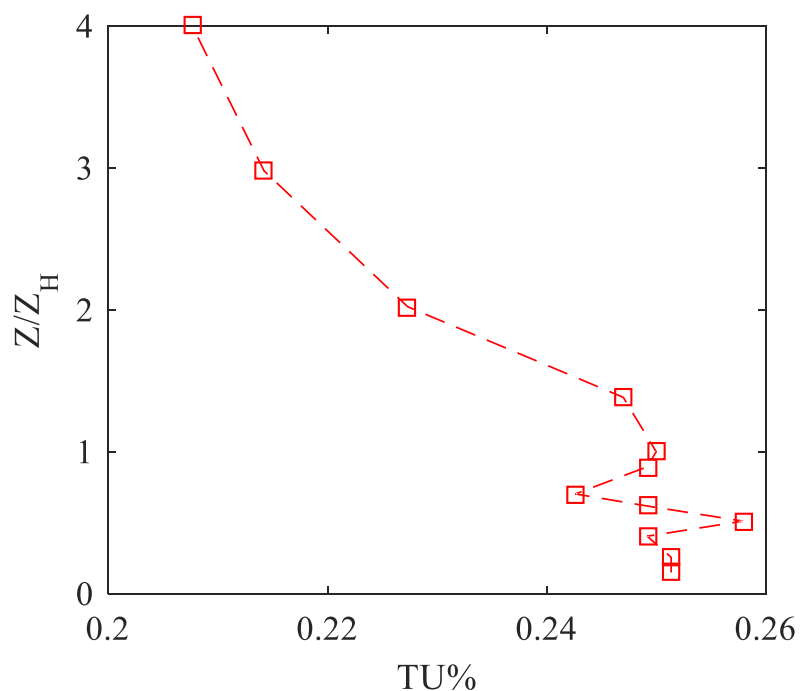

(b)

Figure 6 Vertical profiles of (a) streamwise velocity and (b) turbulent intensity (Tamura 2012)

\subsection{Design of Computational Experiment for the Closure Coefficients Study}

In order to find suitable values for the closure coefficients of the standard $k-\varepsilon$ model, a linear sensitivity analysis based on a proposed methodology by authors (Shirzadi, Mirzaei et al. 2017), was performed for different urban area densities. The values of the closure coefficients, i.e. $C_{\varepsilon 1}$, $C_{\varepsilon 2}, C_{\mu}$ and $\sigma_{k}$, were varied in a specified range as shown in Table 1 . The range of these coefficients was chosen with regards to the previous studies in literature while the value of $\sigma_{\varepsilon}$ was based on the physics of the fully developed channel flow in the log-law region expressed as below (Pope 2001):

$$
\sigma_{\varepsilon}=\frac{\kappa^{2}}{C_{\mu}^{1 / 2}\left(C_{\varepsilon 2}-C_{\varepsilon 1}\right)}
$$

The OFAT (one-factor-at-a-time) sensitivity analysis method (Campolongo, Cariboni et al. 2007) was used in this study which consists of varying one input parameter (i.e. closure coefficients) at a time while keeping all other parameters fixed at their nominal values (i.e. standard values in Table 1). For each input parameter, 10 uniformly distributed samples were considered for the sensitivity analysis. The values of the surface-averaged wind pressure difference $\left(\Delta C_{P}\right)$ over the windward and leeward facades were calculated for each sample and their relative deviations to the measured mean values were assumed as the objective function for the parametric study:

Objective function $=\frac{\Delta C_{P}{ }^{\text {experiment }}-\Delta C_{P}{ }^{C F D}}{\Delta C_{P}{ }^{\text {experiment }}} \times 100$

Table 1 Default value and range of the closure coefficients for the parametric study

\begin{tabular}{ccccc} 
& $C_{\varepsilon 1}$ & $C_{\varepsilon 2}$ & $\sigma_{k}$ & $C_{\mu}$ \\
\hline Standard value & 1.44 & 1.92 & 1.00 & 0.09 \\
Ranges & $1.00-1.50$ & $1.70-3.20$ & $0.8-1.40$ & $0.05-0.15$
\end{tabular}




\section{RESULT AND DESCUTION}

\subsection{Validation Study}

In order to show the reliability of the mesh and CFD solver settings, a validation study was conducted for a case with $C_{A}=0$, in which numerical results for streamwise velocity, TKE, and airflow rate were compared with the experimental results by Tominaga and Blocken (2015). In Figure 7, vertical profiles of the streamwise velocity and TKE alongside of two vertical lines near the windward $(x / D=0.125)$ and leeward openings $(x / D=0.875)$ are plotted for the standard $k-\varepsilon$ and SST models, while the experimental results by Tominaga and Blocken (2015) are shown for comparison study. The streamwise velocity predictions of both turbulence models are very close to the experiment, especially near the inlet jet where the velocity gradient is high. The streamwise velocity gradient decreases near the leeward opening where both turbulence models show acceptable results. Both turbulence models accurately predict the value of TKE near the incoming jet, but they under-predict the near wall distribution of TKE. The same results are obtained for the TKE distribution near the outlet opening where CFD models fail to estimate the vertical distribution of TKE at the areas far from the opening. This is mainly due to the incapability of steady RANS models in calculating the highly unsteady behavior of the flow parameters inside and outside the building, which include the large-scale fluctuations around the building and the flapping jet around the incoming jet inside the building. The mass flow perdition errors of the standard $k-\varepsilon$ and SST models are $5.6 \%$ and $6.5 \%$, respectively, for the unsheltered building model. It can be concluded that the considered cylindrical domain with the applied solver and mesh settings are reliable for prediction of the air flow behavior around and inside the building; therefore, the model settings were preserved for the CFD simulations of other scenarios.

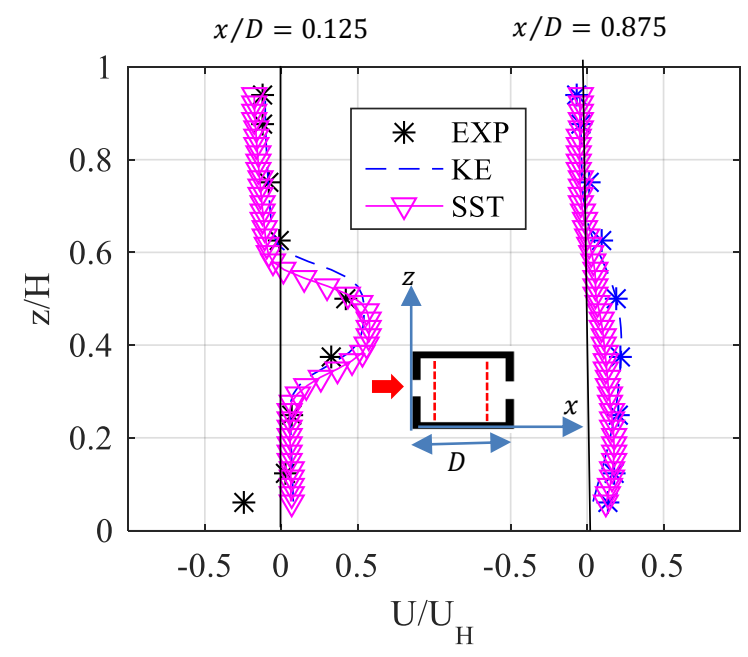

(a)

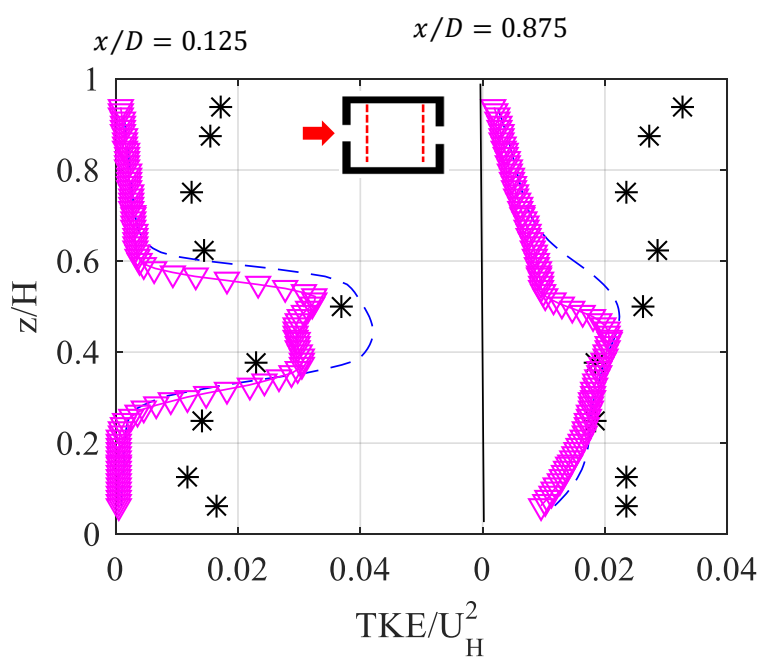

(b)

Figure 7 Vertical profiles of (a) streamwise velocity and (b) TKE along two vertical lines at $x / D=0.125$ and $x / D=0.875$ for $C_{A}=0$ (Tominaga and Blocken 2015)

\subsection{Velocity distribution for different scenarios}

In Figure 8, contours of the velocity $\left(\frac{V}{U_{H}}\right)$ are plotted for urban area densities of 0.2, 0.4, and 0.6 for normal wind direction in regular and staggered arrangements. There was no velocity 
measurement, rather than the pressure, in the experiment and thus only CFD predictions by the standard $k-\varepsilon$ model are provided. For the case of $C_{A}=0.2$, the velocity magnitude around the buildings in the inner area are significantly higher than the cases with higher urban densities. As the urban area density increases, magnitude of the velocity field decreases significantly. The sheltering effect on velocity reduction is more effective for the staggered arrangement comparing with the regular arrangement as lower velocities are observed around the buildings.

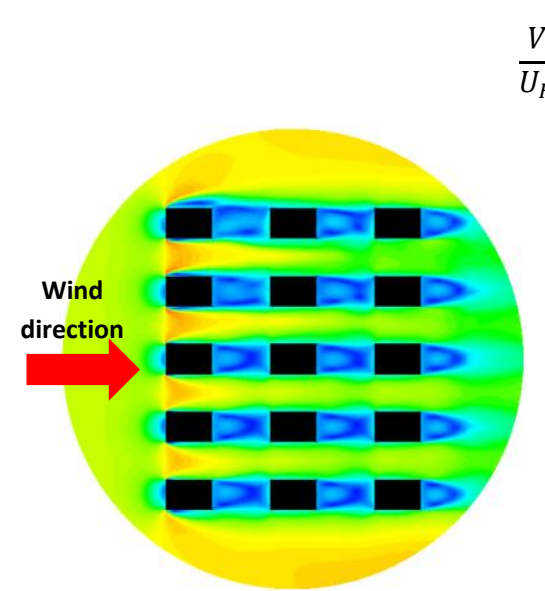

Regular $C_{A}=0.2$

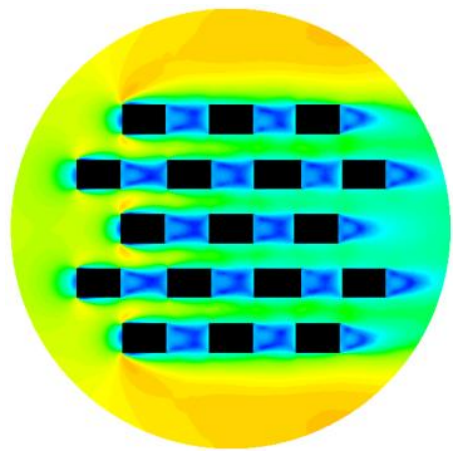

Staggered $C_{A}=0.2$

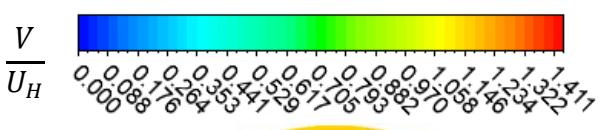

Figure 8 Contours of the velocity $\left(V / U_{H}\right)$ for different urban area densities and building arrangements in normal wind direction

\subsection{Surface-averaged Wind Pressure}

As illustrated in Figure 9, the values of $\Delta C_{P}$ (see Eq.(2)) are calculated for different wind angles and urban area densities for the regular arrangement. Numerical values are compared with the mean value of the surface-averaged wind pressure from the experiment while the negative and positive extreme values of the measurements are also considered. For the case of the isolated building model $\left(C_{A}=0\right)$, the accuracy of RANS turbulence models are acceptable as reported in many studies. The experimentally measured mean values of $\Delta C_{P}$ for wind angles of $0^{\circ}, 30^{\circ}, 60^{\circ}$, and $90^{\circ}$ are $0.87,0.91,0.60$, and 0 , respectively. The calculated values of $\Delta C_{P}$ by the standard $k-\varepsilon$ and $S S T$ models are $1.31,1.29,0.91,0$, and $0.84,0.92,0.55,0$, respectively. It can be seen that the estimated values of the surface-averaged $C_{P}$ for the seal-body (SB) scenario are very close to those values calculated for the cross-ventilated (CV) scenario. 
The mean surface-averaged pressure difference decreases from 0.87 to 0.47 as the urban area density increases from 0 to 0.2 for the normal wind angle. In such scenarios $\left(C_{A}=0.2\right)$, the advantage of the standard $k-\varepsilon$ model over the SST model becomes evident as it predicts the pressure difference over the windward and leeward surfaces more accurately for all wind direction. The relative errors in calculation of $\Delta C_{P}$ for wind angles of $0^{\circ}, 22.5^{\circ}, 45^{\circ}$, and $67.5^{\circ}$ are $25 \%, 10 \%, 4 \%$, and $28 \%$ for the standard $k-\varepsilon$ and $54 \%, 40 \%, 20 \%$, and $45 \%$ for the $S S T$ model, respectively. The results of the SST model are very close to the lower bound of the measurement.

As the urban areas density increases to the value of $C_{A}=0.4$, the pressure difference further decreases and reaches to a value of $\Delta C_{P}=0.2$, which is half of the one measured for $C_{A}=0.2$ at normal wind angle. In this case, the accuracy of both turbulence models decrease noticeably as they under-predict the pressure difference for all wind angles. The relative errors in calculation of $\Delta C_{P}$ for wind angles of $0^{\circ}, 22.5^{\circ}, 45^{\circ}$, and $67.5^{\circ}$ are $49 \%, 48 \%, 53 \%, 48 \%$, and $87 \%, 74 \%, 51 \%, 61 \%$, for the standard $k-\varepsilon$ and $S S T$ models, respectively. The accuracy of the standard $k-\varepsilon$ model is higher; however, results should be used cautiously for the crossventilation calculations because the predicted values are very close to the negative extreme ranges of the measurement, which may not be enough to drive the airflow inside the building. The SST model predictions are out of the expected ranges of the measurement and therefore not very reliable in most of the scenarios.

For the highest areas density of $C_{A}=0.6$, the lowest value of pressure difference of about $\Delta C_{P}=$ 0.04 is experimentally measured for the normal wind direction. In this case, not only the CFD models underestimate the value of the pressure difference, but they also fail to capture the trend of the $C_{P}$ variation against the wind angle in comparison with the experiment. The estimated value of $\Delta C_{P}$ for the standard $k-\varepsilon$ model for normal wind angle is 0.03 , which is very close to the experiment, but as the wind angle increases, the accuracy of the CFD model decreases significantly and even reaches to negative values of -0.04 and -0.01 for the wind angles of $45^{\circ}$ and $67.5^{\circ}$. The $S S T$ model completely fail to estimate the pressure coefficient as it predicts a near zero value for $\Delta C_{P}$ in all wind directions. The maximum relative errors in calculating the $\Delta C_{P}$ are obtained for wind angle of $45^{\circ}$, which are $158 \%$ and $125 \%$ for the standard $k-\varepsilon$ and SST models, respectively.

The variation of the surface-averaged pressure difference across the windward and leeward openings $\left(\Delta C_{P}\right)$ against wind angle and urban area density $\left(C_{A}\right)$ is shown in Figure 10 for the staggered arrangement. The experimentally measured mean values of $\Delta C_{P}$ are $0.42,0.55,0.39$, 0.40 , and 0.02 for wind angles of $0^{\circ}, 22.5^{\circ}, 45^{\circ}, 67.5^{\circ}$, and $90^{\circ}$, respectively. This values are very close to the regular arrangement with an exception for the wind angle of $45^{\circ}$ where $\Delta C_{P}$ decreases from 0.59 for the regular arrangement to 0.39 for the staggered arrangement. For the case with $C_{A}=0.2$, the accuracy of the RANS models are acceptable, but they are lower than the CFD accuracy for the regular arrangements. The relative errors for the standard $k-\varepsilon$ and SST models vary in the range of $18 \%$ to $48 \%$ and $5 \%$ to $96 \%$, respectively. The accuracy of the SST model for the wind angle of $90^{\circ}$ decreases rapidly as it over-predicts the pressure difference. 

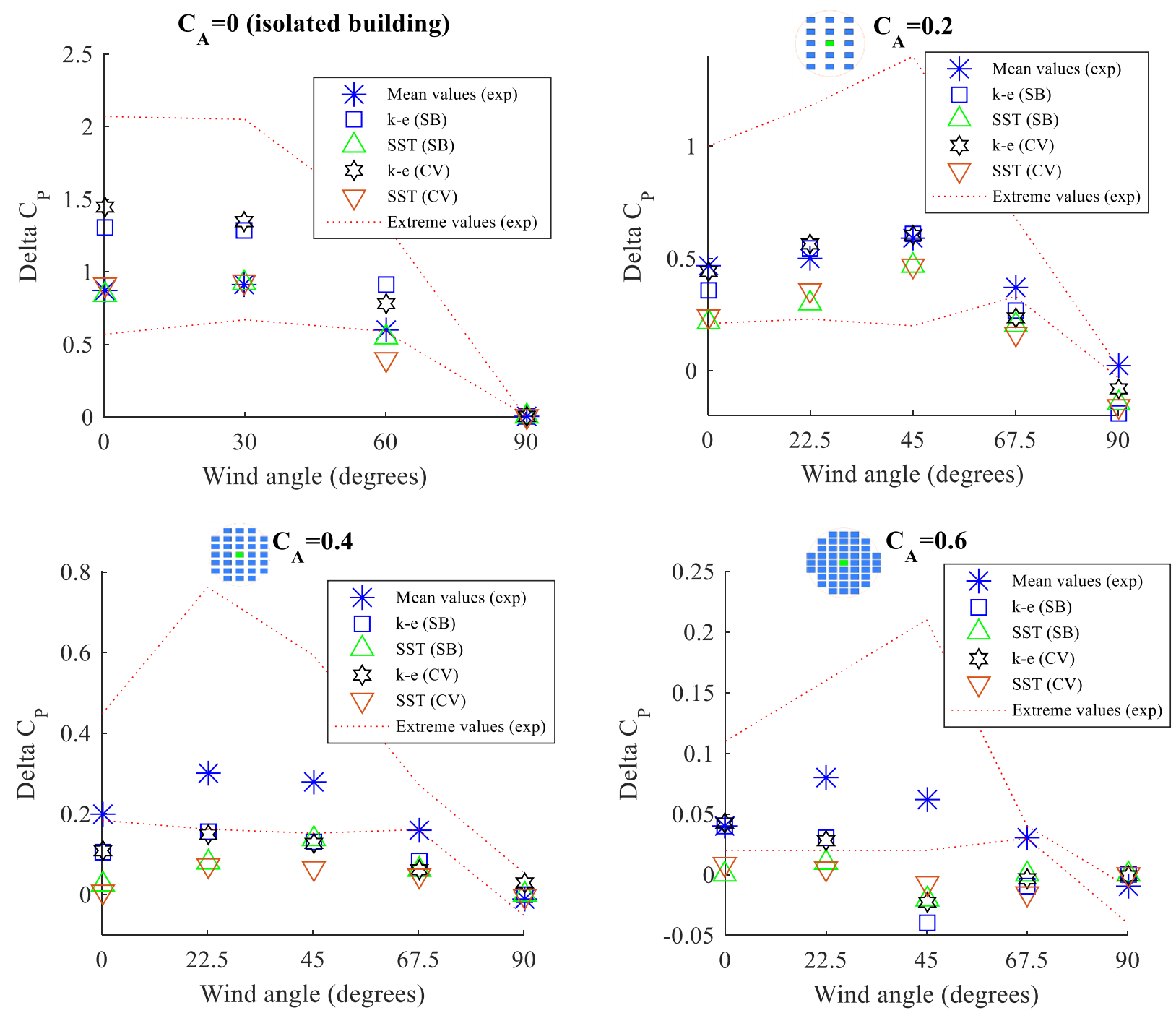

Figure 9 The variation of the wind surface pressure difference for the regular arrangement of buildings for SB and CV scenarios

As the area density reaches to $C_{A}=0.4$, the accuracy of the RANS models dramatically fail similar to the observed values for the regular arrangement. In this case, the relative errors in calculation of $\Delta C_{P}$ for the standard $k-\varepsilon$ and $S S T$ models are $88 \%, 81 \%, 64 \%, 65 \%$, and $91 \%$, $99 \%, 108 \%, 37 \%$, respectively. In the case of the regular arrangement, despite the low accuracy of the RANS models, a more similar trend to the experiment comparing to the staggered arrangement is simulated. A similar situation is found for the case with the highest area density of $C_{A}=0.6$ where the average of the relative errors in estimation of $\Delta C_{P}$ for all wind directions are found to be about $103 \%$ and $138 \%$ for the standard $k-\varepsilon$ and $S S T$ models, respectively. 

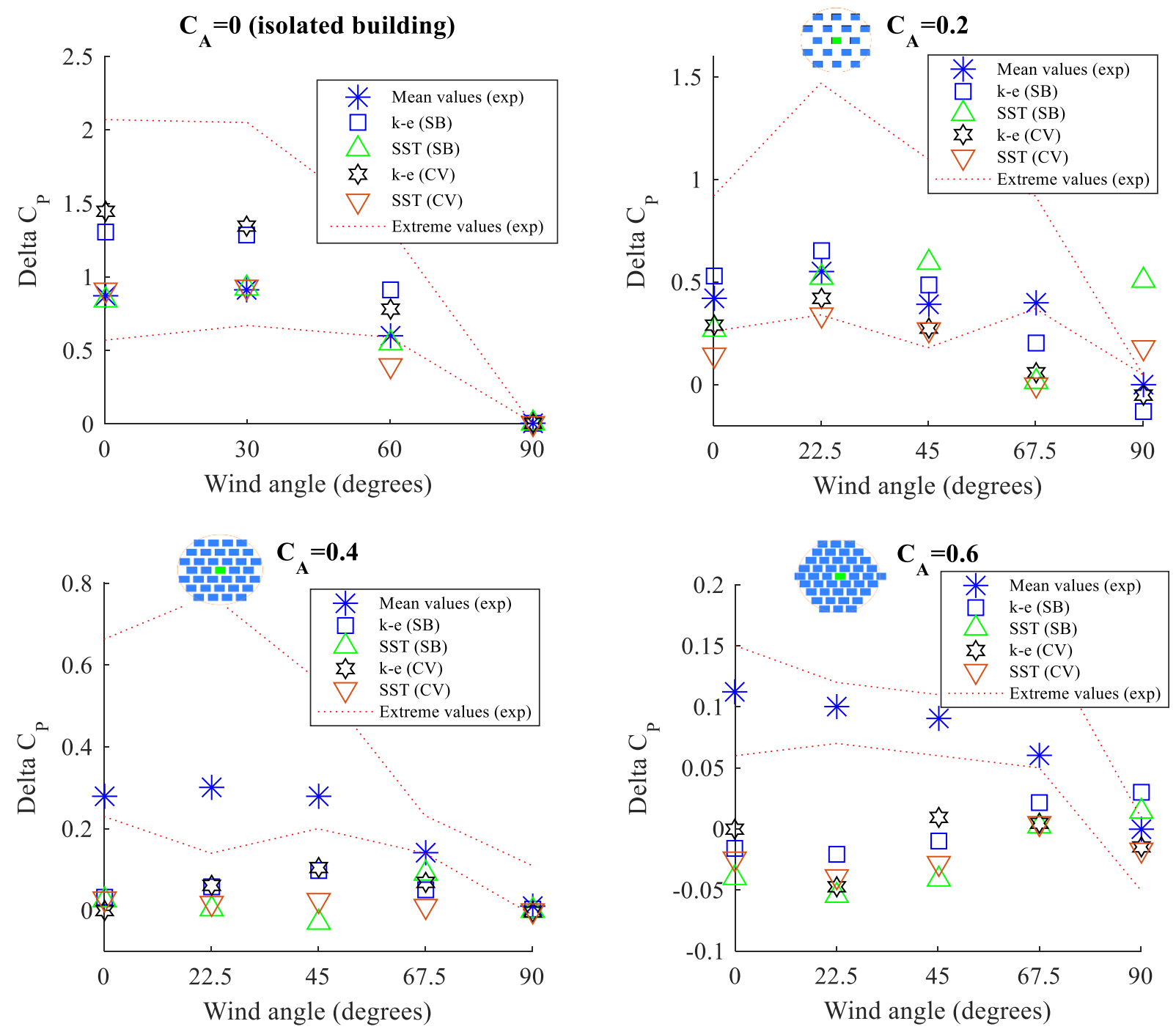

Figure 10 The variation of the wind surface pressure difference for the staggered arrangement of buildings for SB and CV scenarios

\subsection{Local Surface Wind Pressure Distribution}

In the previous sections, the variation of the surface-averaged wind pressure and its effect on the airflow rate calculations were discussed, however, as emphasized in many studies, the local variation of the wind pressure has a noticeable impact on the cross-ventilation performance and the associated uncertainties. Thus, in Figure 11, contours of the pressure difference across the windward and leeward facades $\left(\Delta C_{P}\right)$ are plotted for different urban area densities against the normal wind angle. In this figure, numerical results obtained by the standard $k-\varepsilon$ and $S S T$ models are compared with the mean values from the experiment. The highest value of $\Delta C_{P}$ for the isolated building model is measured at the upper half of the building façade where the SST model predicts a very close value to the experimental data while the standard $k-\varepsilon$ overestimates the wind pressure difference. When the area density increases to $C_{A}=0.2$, despite the acceptable results for the surface-averaged wind pressure (see Figure 9), the accuracy of the CFD model in prediction of the local wind pressure decreases. The standard $k-\varepsilon$ model predicts the location of the maximum $\Delta C_{P}$ very close to the experiment, but it 
underestimates the pressure distribution at the lower part of the façade. The SST model shows a completely different pattern in comparison with the one measured experimentally.

For the case of $C_{A}=0.4$, the distribution of the $\Delta C_{P}$ near the roof predicted by the standard $k-\varepsilon$ model is close to the experiment, but the level of $\Delta C_{P}$ is underestimated over the areas far from the roof. In this case, the $S S T$ model fails to estimate the pressure distribution as it predicts $\Delta C_{P}=0$ across the facade.
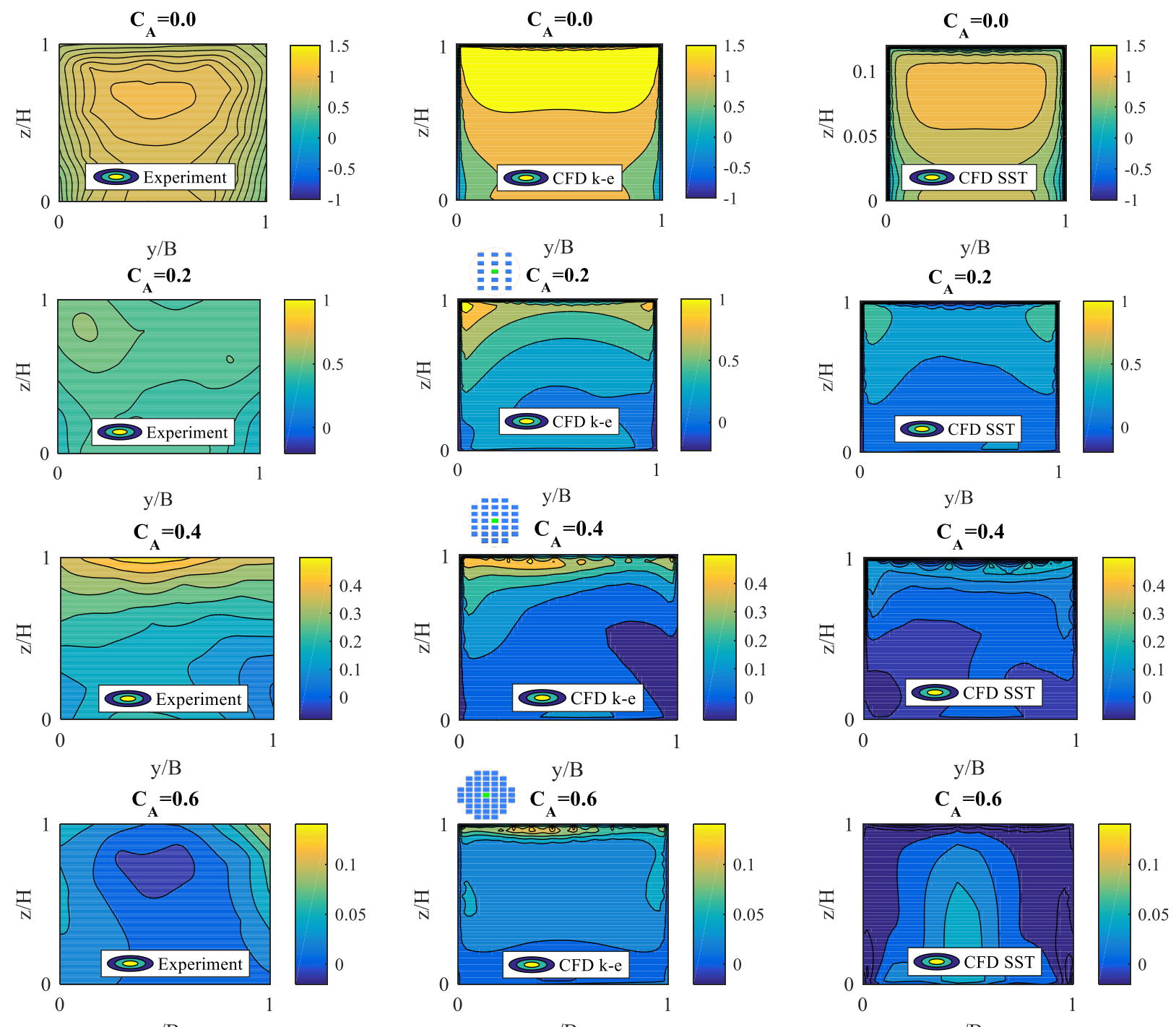

Figure 11 Contours of the surface wind pressure difference for the wind angle of $0^{\circ}$ in the regular arrangement of buildings

As the urban area density further increases to $C_{A}=0.6$, the deviation between the experimental measurement and the RANS results becomes more evident. Both the standard $k-\varepsilon$ and $S S T$ models fail to calculate the local distributions of the pressure difference. These results highlight on the low accuracy of steady RANS models in prediction of the local distribution of the wind pressure and again emphasize on the limitations of such models in modeling of the crossventilation in highly-packed urban areas. For instance, according to the presented results, it is 
not practical to investigate the effect of the opening positions on the cross-ventilation performance for area densities larger than 0.2 as the investigated RANS models cannot accurately predict the local distribution of the pressure coefficient over the facades.

\subsection{Sensitivity Parametric Study and Model Improvement}

In previous sections, the low accuracy of steady RANS models in prediction of the surfaceaveraged and local wind pressure distributions was shown for the urban area densities larger then $C_{A}=0.2$. Thus, in order to investigate the effect of the closure coefficients on the accuracy of the RANS models, a sensitivity parametric study is done for the regular building arrangement for the wind angles of $0^{\circ}$ and $67.5^{\circ}$ with $C_{A}=0.4$ and $C_{A}=0.6$, respectively. For these two cases, the CFD predictions of the surface-averaged wind pressure difference $\left(\Delta C_{P}\right)$ were out of the measurement ranges with errors up to $120 \%$ (see Figure 9).

In Figure 12, the results of the OFAT sensitivity analysis are shown, where the contours of the relative error in calculation of the surface-averaged wind pressure difference (Eq. 13) are plotted against the closure coefficients. These contours prove that the accuracy of standard $k-\varepsilon$ model depends on the closure coefficients. Specifically, in the case of $C_{A}=0.4$ (see Figure 12a), the relative error in prediction of the surface-averaged wind pressure difference $\left(\Delta C_{P}\right)$ decreases to less than $10 \%$ when $C_{\varepsilon 2}$ increases from its default value of 1.92 to 3.2 . High accurate results also found for low values of $C_{\varepsilon 1}$ in the range of 1 to 1.1 , where the relative error reaches to a minimum value of $10 \%$. According to Figure $12 \mathrm{~b}$, the variation of $C_{\mu}$ has also a significant impact on the accuracy of the standard $k-\varepsilon$ model as the relative error decreases to the value of $10 \%$ for large values of $C_{\mu}$ between 0.12 and 0.15 . Nevertheless, as its shown in Figure $12 \mathrm{c}$, the value of $\sigma_{k}$ has negligible effect on the variation of the relative error in calculating of the surface-averaged wind pressure and thus its default value of $\sigma_{k}=1$ is suitable for the CFD modeling of dense urban areas considered in this study.

For $C_{A}=0.6$ (see Figure $12 \mathrm{~d}$ ), the relative error of the standard $k-\varepsilon$ model decreases from $158 \%$ to $91 \%$ when $C_{\varepsilon 2}$ increases from its default value of 1.92 to 3.2 ; nevertheless, this error is still too high and is not acceptable for the engineering applications. Also, as shown in Figure $12 \mathrm{~d}$, the sensitivity of the standard $k-\varepsilon$ model to the variation of $C_{\varepsilon 1}$ is very limited as the relative error decreases from $158 \%$ to $127 \%$ when $C_{\varepsilon 1}$ declines from 1.4 to 1 . In contrast to the case with $C_{A}=0.4$, very low sensitivity of the CFD model accuracy on the variation of $C_{\mu}$ is obtained for $C_{A}=0.6$ (see Figure $12 \mathrm{e}$ and Figure 12f). The variation of $\sigma_{k}$, as illustrated in Figure 12f, has very low impact on the CFD error, where relative error changes in a narrow range between $135 \%$ and $154 \%$ for $\sigma_{k}$ variation from 0.8 to 1.4 . Results show that the potential of model improvement through closure coefficients calibration is noticeable for the case with $C_{A}=0.4$, but in contrary, the model improvement for $C_{A}=0.6$ is very limited for the considered range of the closure coefficients as shown in Table 1. 


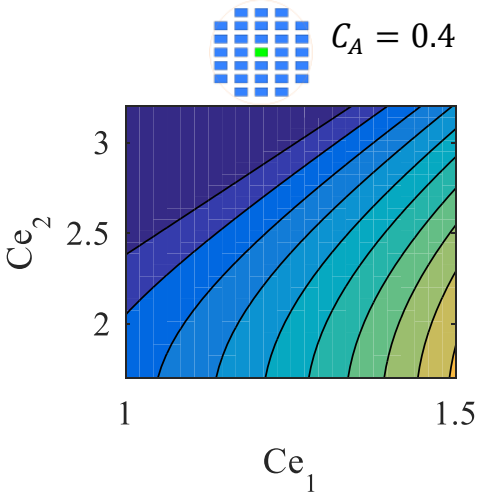

(a)

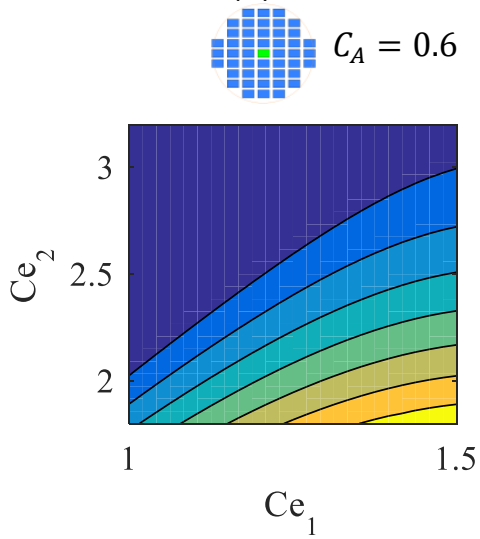

(d)

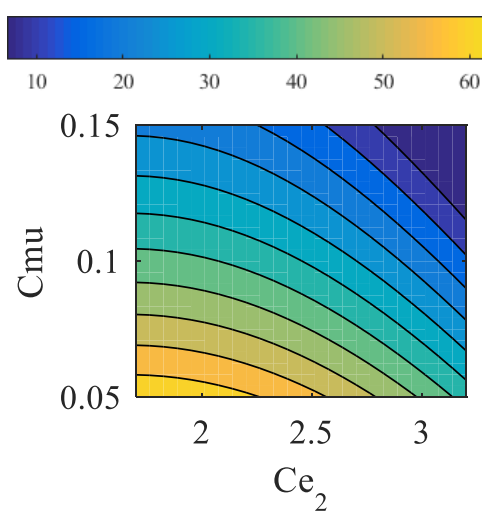

(b)

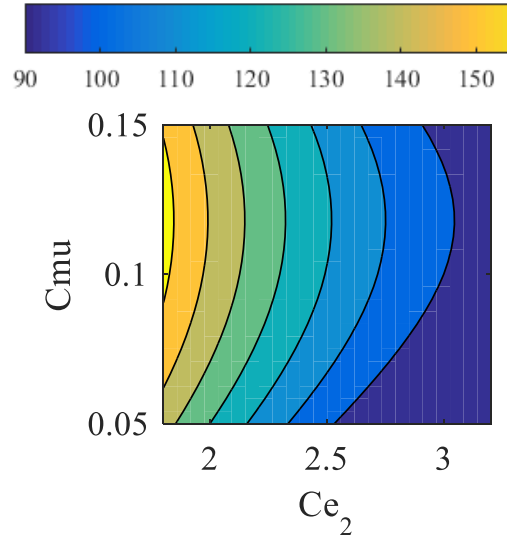

(e)
$\frac{\Delta C_{P}{ }^{\text {experiment }}-\Delta C_{P}{ }^{C F D}}{\Delta C_{P}{ }^{\text {experiment }}} \times 100$

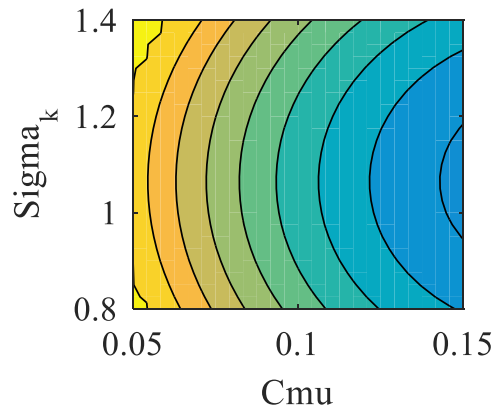

(c)
$\frac{\Delta C_{P}{ }^{\text {experiment }}-\Delta C_{P}{ }^{C F D}}{\Delta C_{P}{ }^{\text {experiment }}} \times 100$

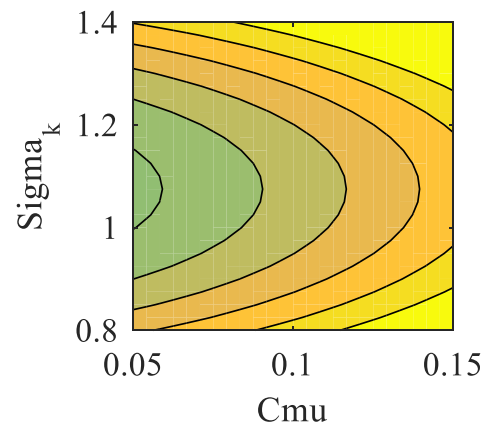

$(\mathfrak{f})$

Figure 12 Effect of the closure coefficients variations on the relative error of the wind surface pressure difference $\left(\Delta C_{P}\right)$ for the regular arrangement and normal wind angle (SB scenario)

It is possible to guess an initial estimation for the optimum values of the closure coefficients using the results of the sensitivity parametric study. To this end, a set of optimum closure coefficients were selected for the case of $C_{A}=0.4$ and RANS models were then simulated to investigate the behavior of the model improvement for other wind angles rather than the normal one for which the sensitivity study was performed. Hence, the following values are considered for CFD simulations as optimum values:

$C_{\varepsilon 1}=1.44, C_{\varepsilon 2}=3.2, C_{\mu}=0.15, \sigma_{k}=1, \sigma_{\varepsilon}=0.27$

In Figure 13, the surface-averaged wind pressure difference is shown for the standard $k-\varepsilon$ with default and modified closure coefficients for the regular arrangement and results are compared with the experimental data. The relative errors of the CFD model for wind angles of $0^{\circ}, 22.5^{\circ}, 45^{\circ}$, and $67.5^{\circ}$ decrease from $49 \%, 48 \%, 53 \%$, and $48 \%$ for the default coefficients to $12 \%, 29 \%, 27 \%$, and $21 \%$ for the modified coefficients. The predicted values are within the range between the negative and positive extreme values determined in the experiment. 


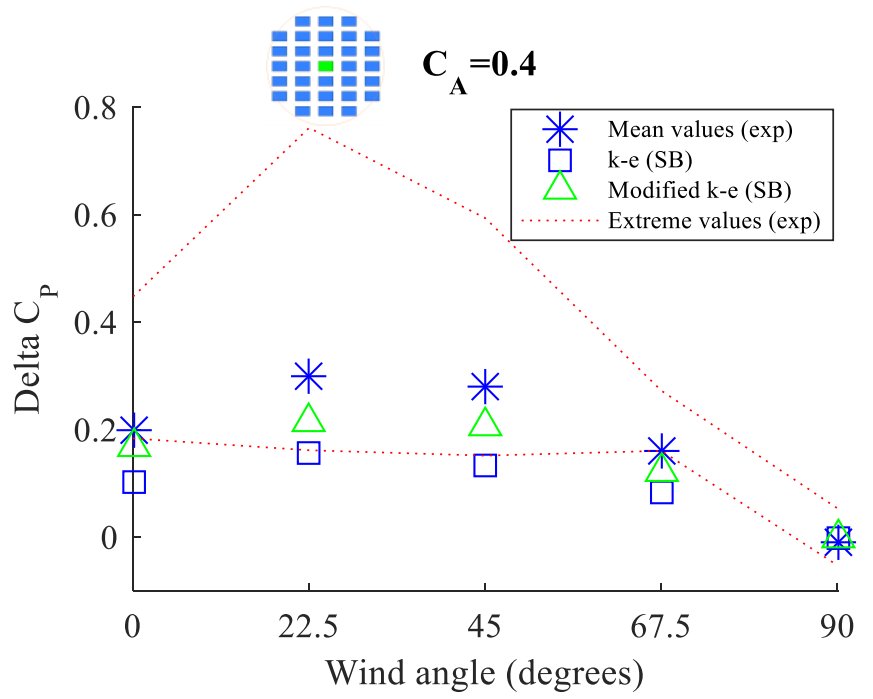

Figure 13 Surface-averaged wind pressure difference $\Delta C_{P}$ for different wind angles in $C_{A}=0.4$ and regular arrangement

Contours of $\Delta C_{P}$ for $C_{A}=0.4$ are shown in Figure 14 against different wind angles for the default and modified closure coefficients in the regular arrangement. The distributions of the mean values of the surface pressure difference from the experiment are also depicted for the comparison purpose. For the normal wind angle of $0^{\circ}$, the pressure coefficient distribution pattern changes with the modified coefficients in a way that it is more similar to the experiment compared to the one obtained using the default coefficients. In the CFD model, there are two areas at the upper half corners where the values of $\Delta C_{P}$ are locally high, but such pressure peaks cannot be seen in the experiment. When wind angle increases to $22.5^{\circ}$, the highpressure area moves to the upper left corner, which is predicted more accurately by the modified model compared to the default model. In this case, both CFD models under-predict the pressure coefficient difference $\left(\Delta C_{P}\right)$ over the center of the façade. The distribution of $\Delta C_{P}$ contours remain constant for the wind angles of $45^{\circ}$ and $67.5^{\circ}$ while the pressure difference level decreases as wind angle increases. In this case, RANS models estimate the similar pattern for the pressure difference distribution while the accuracy of the modified model is significantly higher than the default model at the left corner. The model improvement is mainly contributed to the growth of the momentum diffusion and TKE inside the cavities around the target building and surrounded buildings, which is obtained by altering the contribution of the diffusion, production, and dissipation terms of the $k-\varepsilon$ equations. In general, the modified model shows significant improvement in prediction of the pressure coefficient at areas where pressure coefficient are high, but the prediction accuracy is not noticeably improved at the areas with a low pressure coefficient. 

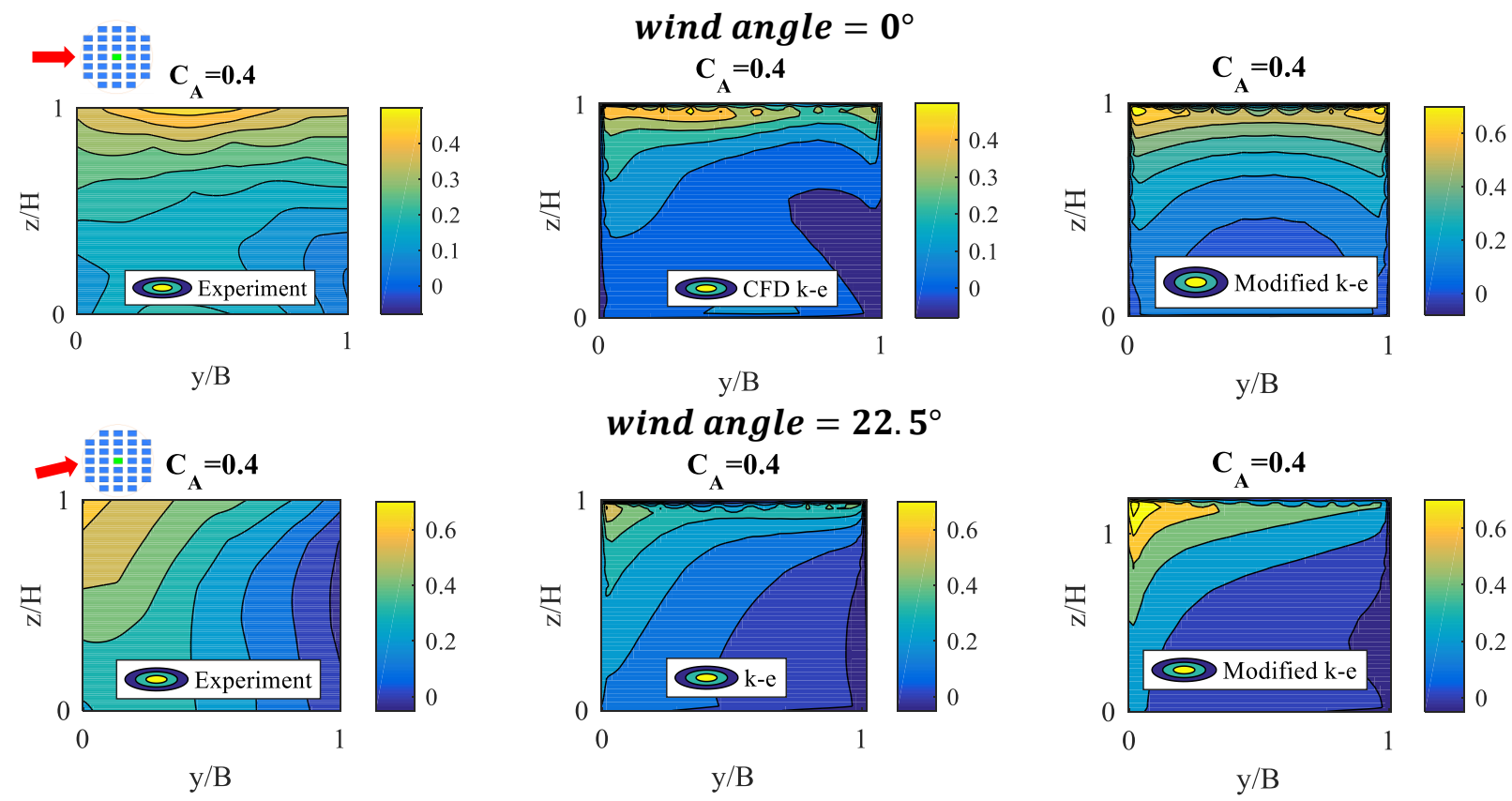

wind angle $=22.5^{\circ}$
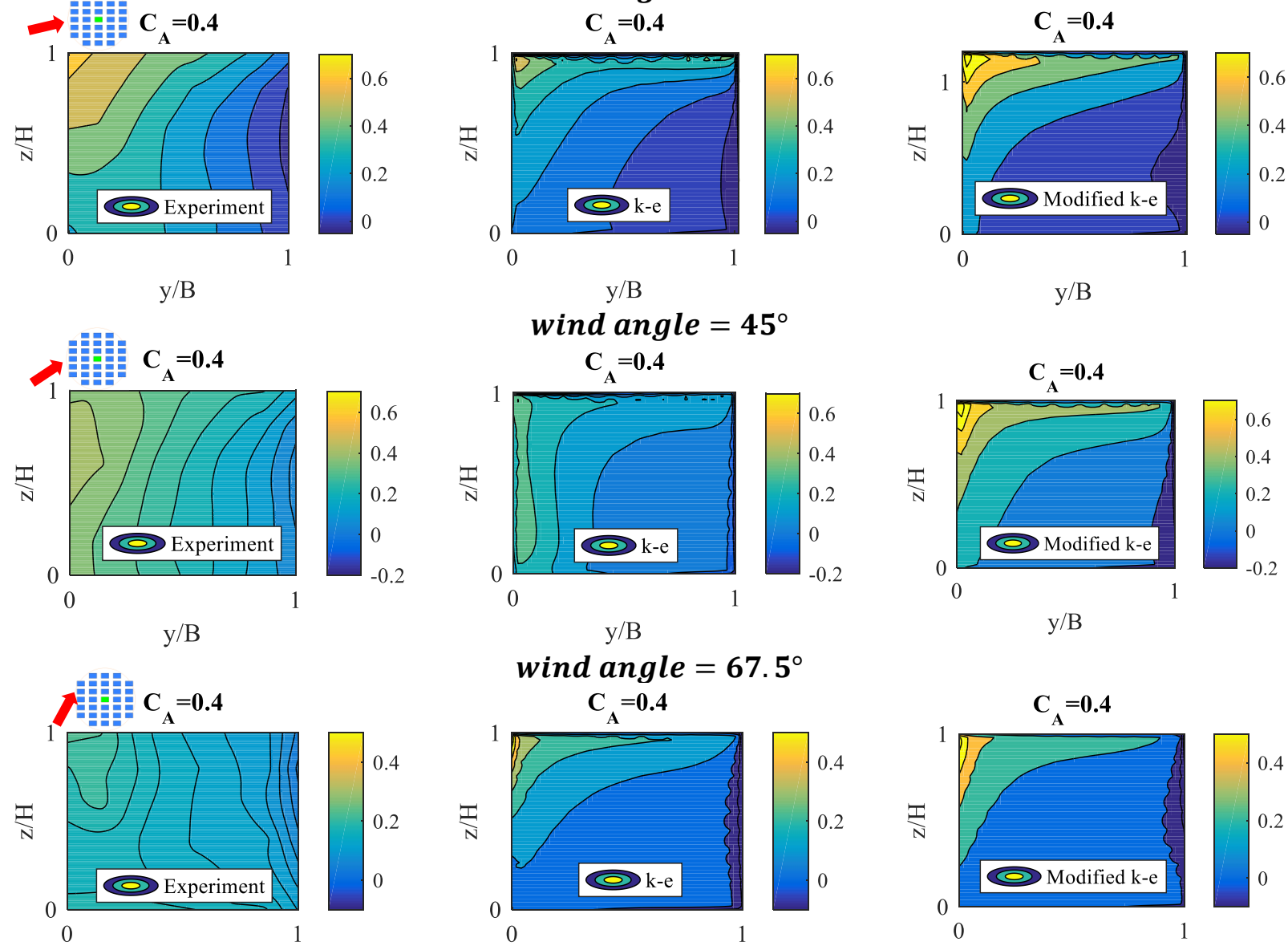

wind angle $=67.5^{\circ}$
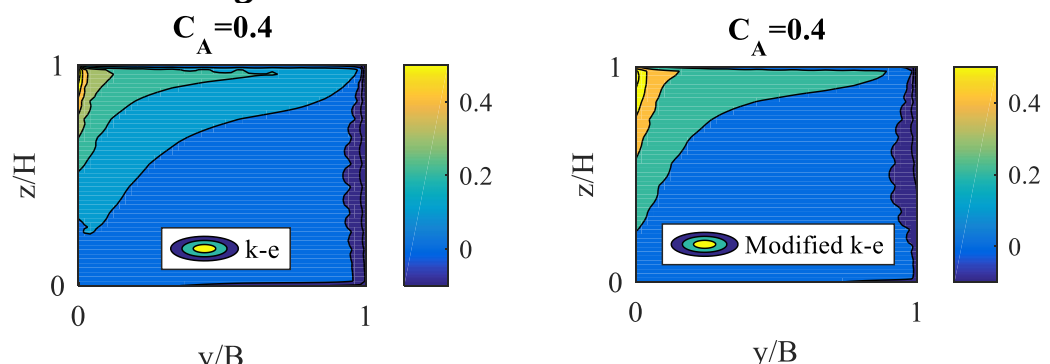

Figure 14 Contours of $\Delta C_{P}$ for different wind angles obtained by the RANS model using the default and modified closure coefficients

\subsection{Airflow Rate}

The accuracy of the RANS models in prediction of the crossing airflow rate for different urban morphologies is discussed in this section. It is noteworthy to mention that there is no airflow rate measurement in the Tamura (2012) as they considered sealed-body model. The only available experiment for airflow rate measurement is the research which was carried out by Tominaga and Blocken (2015) in which the crossing airflow rate through the windward opening of a generic building model was measures using the tracer gas method. The urban area density in their model was $C_{A}=0.25$. The surrounding buildings in their work were 9 cuboidal building 
models, which were positioned in the regular arrangement. The wall porosity of their model was $10 \%$ and the openings were at the middle height of the windward and leeward facades. A separate CFD simulation was conducted for this case while all CFD settings described in section 2.3.2 were applied to the model.

The variations of the non-dimensional airflow rate (see Eq.(3)) against the wind angle are shown in Figure 15 for the regular and staggered arrangements in different urban area densities. In the case of the isolated building (Figure 15a), the airflow rate predictions by the standard $k-\varepsilon$ and SST models are about 0.6 and 0.5 for the wind angles of $0^{\circ}$ and $30^{\circ}$, respectively. For the isolated building model, as shown in Figure 9, the predicted values of $\Delta C_{P}$ by the standard $k-\varepsilon$ model are higher than those are predicted by the SST model for all wind angles, resulting in higher predictions of the passing airflow rate through the openings. The highest discrepancy between the RANS models occurs at $60^{\circ}$ wind angle where the airflow rates are estimated to be 0.19 and 0.11 for the standard $k-\varepsilon$ and SST models, respectively.

When urban area density increase to 0.2 , as illustrated in Figure 15b, the predicted airflow rate by CFD decreases to less than one-third of the one predicted for the isolated building for normal wind angle in staggered and regular arrangements. The difference between the airflow rate predictions by the standard $k-\varepsilon$ and SST models are significant, which is a direct result of the different predictions of $\Delta C_{P}$ by these models (see Figure 9). For the regular arrangement, the estimated airflow rate grows monotonically as wind angle increases from $0^{\circ}$ to $45^{\circ}$ but it decreases for higher wind angles. In contrary, for the staggered arrangement, the predicted airflow rate remains constant when wind angle rises from $0^{\circ}$ to $45^{\circ}$. The values of the airflow rate predictions for the regular arrangement are generally higher than the staggered arrangement.

For the larger urban area densities than 0.2 , not only the predicted values of the passing airflow rate significantly decline, but also the discrepancy between the results by the standard $k-\varepsilon$ and SST models surge dramatically. For instance, in the regular arrangement with $C_{A}=0.4$, a negative value of the airflow rate is predicted by the SST model for the wind angle of $0^{\circ}$ while a positive value of the airflow rate is estimated by the standard $k-\varepsilon$ model. The deviations between the two turbulence models become even larger when urban area density rises to $C_{A}=$ 0.6. The illustrated deviations between the airflow prediction by different RANS models for highly-packed urban areas is directly linked to the inaccurate prediction of the wind pressure over the windward and leeward facades as shown in Figure 9 and Figure 10. 


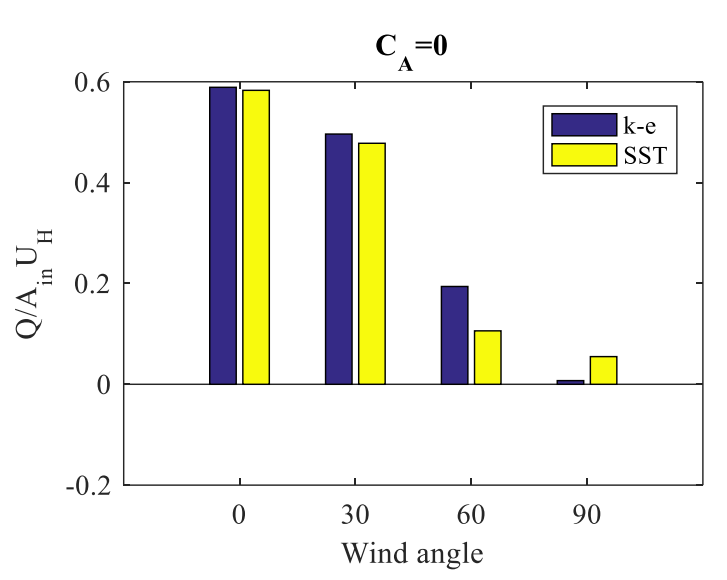

(a)

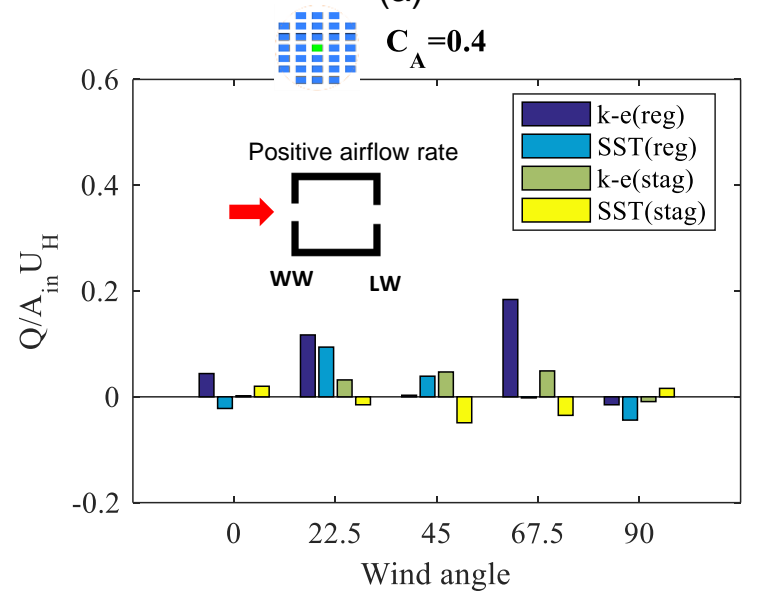

(c)

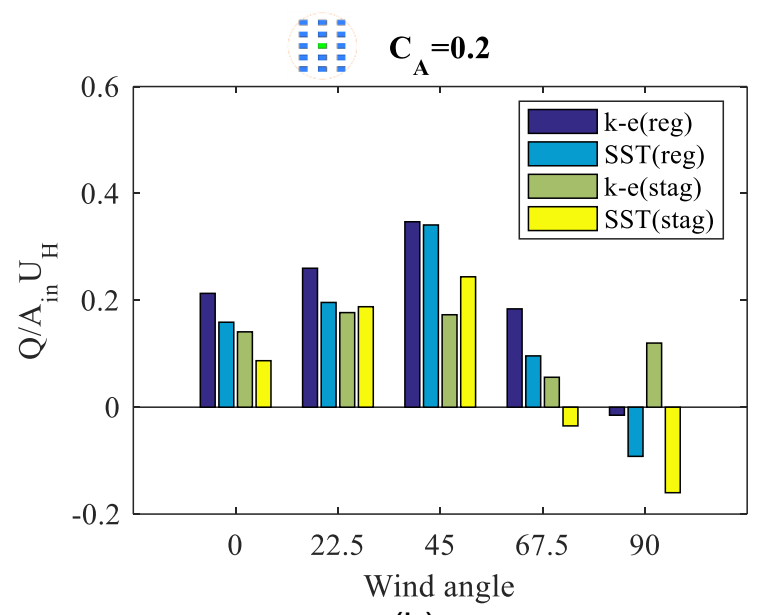

(b)

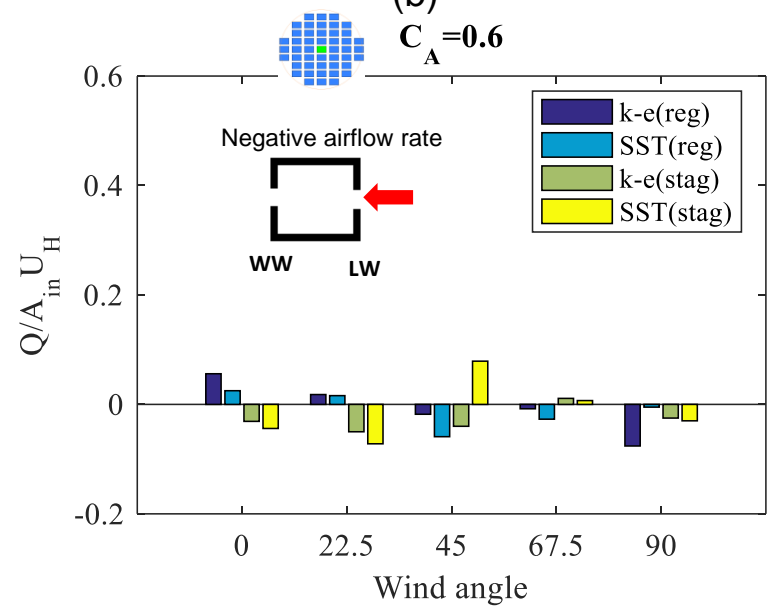

(d)

Figure 15 The non-dimensional airflow rate $\left({ }^{Q} / A_{A_{\text {in }} U_{H}}\right)$ for regular and staggered arrangements

$$
\text { in (a) } C_{A}=0.0 \text {, (b) } C_{A}=0.2 \text {, (c) } C_{A}=0.4 \text {, (d) } C_{A}=0.6
$$

The effect of the closure coefficients modification on the airflow rate prediction is shown in Table 2, where results of the standard $k-\varepsilon$ and modified $k-\varepsilon$ models are shown for the regular arrangement in $\mathrm{C}_{\mathrm{A}}=0.25$ and $\mathrm{C}_{\mathrm{A}}=0.4$. The values of the modified closure coefficients (see Eq.(14)) were applied to the cross-ventilation (CV) models of these two urban area densities. In the case of $\mathrm{C}_{\mathrm{A}}=0.25$, CFD predictions by the standard and modified $k-\varepsilon$ model are compared with the experimental measurement by Tominaga and Blocken (2015), in which a value of 0.07 was reported for the non-dimensional airflow rate. A value of about 0.00 was found by the standard $k-\varepsilon$ model, while the modified model predicted a value of about 0.06 , which is very close to the experiment. There were no experimental measurements for other wind angles than $0^{\circ}$. For the case with $\mathrm{C}_{\mathrm{A}}=0.4$, there is no experimental data, thus only CFD predictions of airflow rate are shown. The calculated non-dimensional airflow rate by the standard and modified RANS models are respectively $0.04,0.12,0,0.01$, and $0.06,0.10,0.05,0.01$ for wind angles of $0^{\circ}, 22.5^{\circ}, 45^{\circ}$, and $67.5^{\circ}$.

In general, the numerical results prove that the application of the steady RANS models in highlypacked urban areas should be considered with more cautious. Obviously, wind tunnel 
experiments on airflow rate measurements are required to determine the accuracy of the steady RANS models for cross-ventilation modeling in highly-packed urban areas.

\begin{tabular}{|c|c|c|c|c|c|c|}
\hline \multicolumn{7}{|c|}{ Table 2 The non-dimensional airflow rate $\left({ }^{Q} / A_{\text {in }} U_{H}\right)$} \\
\hline$\frac{Q}{U_{H} A_{i n}}$ & Wind angle & $0^{\circ}$ & $22.5^{\circ}$ & $45^{\circ}$ & $67.5^{\circ}$ & $90^{\circ}$ \\
\hline$C_{A}=0.25$ & Standard $k-\varepsilon$ & 0.00 & & & & \\
\hline 0 & Modified $k-\varepsilon$ & 0.06 & & & & \\
\hline & experiment & 0.07 & & & & \\
\hline$C_{A}=0.4$ & Standard $k-\varepsilon$ & 0.04 & 0.12 & 0.00 & 0.01 & -0.02 \\
\hline 舴 & Modified $k-\varepsilon$ & 0.06 & 0.10 & 0.05 & 0.01 & 0.00 \\
\hline
\end{tabular}

\section{CONCLUSION}

A series of steady RANS simulations were done for building blocks, which were arranged in different urban area densities in regular and staggered orders to mimic the highly-packed urban areas in cities. Different RANS turbulence models were utilized to predict the surface-averaged pressure difference over the windward and leeward facades and crossing airflow through the openings against different wind angles. The values of the predicted surface-averaged pressure coefficients were compared with the experimental measurements, which were conducted in an atmospheric boundary layer wind tunnel over a sealed-body model. The results of the steady RANS models were compared with the mean value of the pressure coefficients. In order to consider the uncertainty of the measurement and also the fluctuating behavior of the surface pressure, the statistically calculated positive and negative extreme values from the experiment were also considered. Moreover, a sensitivity parametric study was employed to investigate the possibility in accuracy improvement of the RANS models by calibrating the closure coefficients of the turbulence models. Numerical results show that the accuracy of RANS models decreases significantly for highly-packed urban areas where CFD reliability should be considered more cautiously. The following findings are considered as the main conclusion of this study:

- The accuracy of the steady RANS is acceptable for urban area densities less than $C_{A}=$ 0.2 where the estimated surface-averaged wind pressures fall inside the expected measurement range of the positive and negative extreme values of the experiment.

- The cross-ventilation airflow prediction of the steady RANS is acceptable for the same range of the urban area densities.

- For urban area densities larger than $C_{A}=0.2$, the accuracy of the steady RANS models decreases significantly as the predicted values for the surface-averaged wind pressure are outside the expected ranges from the experiment.

- For urban area density of $C_{A}=0.4$ in regular arrangement, the standard $k-\varepsilon$ model provides acceptable results at some limited wind angles, but the predicted values are very close to the lower bound of the experimental range.

- For area densities of 0.4 and 0.6 , negative airflow rates are estimated against some wind directions as a result of the incorrect surface pressure estimation. 
- A significant model improvement is possible by calibrating the closure coefficients for urban area density of 0.4 where prediction errors are decreased up to $45 \%$ for the regular arrangement.

- For higher urban densities than 0.4, more advanced calibration methodologies such as stochastic optimization are required to reach acceptable results.

Further simulation studies and wind tunnel airflow rate measurements, are, thus, required to improve the RANS models accuracy for wind-related studies at highly-packed urban areas.

\section{ACKNOWLEDGEMENT}

The authors would like to express their gratitude to the University of Guilan for their financial support.

\section{References}

Akamine, Y., T. Kurabuchi, M. Ohba, T. Endo and M. Kamata (2004). "A CFD analysis of the air flow characteristics at an inflow opening." International Journal of Ventilation 2(4): 431-437.

Arendt, K., M. Krzaczek and J. Tejchman (2017). Influence of input data on airflow network accuracy in residential buildings with natural wind-and stack-driven ventilation. Building Simulation, Springer.

Asfour, O. S. and M. B. Gadi (2007). "A comparison between CFD and Network models for predicting wind-driven ventilation in buildings." Building and Environment 42(12): 4079-4085.

Aydin, Y. C. and P. A. Mirzaei (2016). Wind-driven ventilation improvement with plan typology alteration: A CFD case study of traditional Turkish architecture. Building Simulation, Springer.

Campolongo, F., J. Cariboni and A. Saltelli (2007). "An effective screening design for sensitivity analysis of large models." Environmental modelling \& software 22(10): 1509-1518.

Cheung, J. O. and C.-H. Liu (2011). "CFD simulations of natural ventilation behaviour in high-rise buildings in regular and staggered arrangements at various spacings." Energy and Buildings 43(5): 11491158.

Chu, C. R., Y.-H. Chiu, Y.-J. Chen, Y.-W. Wang and C.-P. Chou (2009). "Turbulence effects on the discharge coefficient and mean flow rate of wind-driven cross-ventilation." Building and Environment 44(10):

2064-2072.

Costola, D., B. Blocken and J. Hensen (2009). "Overview of pressure coefficient data in building energy simulation and airflow network programs." Building and Environment 44(10): 2027-2036.

Geros, V., M. Santamouris, S. Karatasou, A. Tsangrassoulis and N. Papanikolaou (2005). "On the cooling potential of night ventilation techniques in the urban environment." Energy and Buildings 37(3): 243257.

Guo, W., X. Liu and X. Yuan (2015). "Study on Natural Ventilation Design Optimization Based on CFD Simulation for Green Buildings." Procedia Engineering 121: 573-581.

Handbook, A. F. (2009). "American society of heating, refrigerating and air-conditioning engineers." Inc.: Atlanta, GA, USA.

Hirose, C., A. Hagishima, N. Ikegaya and J. Tanimoto (2014). Large-Eddy Simulation for Turbulent Nature of Flow and Pressure Fields over Urban Building Arrays. in Proceeding of 2nd Asia conference of International Building Performance Simulation Association.

Hu, C.-H., M. Ohba and R. Yoshie (2008). "CFD modelling of unsteady cross ventilation flows using LES." Journal of Wind Engineering and Industrial Aerodynamics 96(10): 1692-1706. 
Hua, C.-H., M. Ohbab and R. Yoshiec (2006). "CFD modelling of cross ventilation using unsteady methods." JWE: 日本風工学研究会誌(108): 255-258.

Kanda, M. (2006). "Large-eddy simulations on the effects of surface geometry of building arrays on turbulent organized structures." Boundary-Layer Meteorology 118(1): 151-168.

Karava, P. (2008). Airflow prediction in buildings for natural ventilation design: wind tunnel measurements and simulation, Concordia University.

Karava, P., T. Stathopoulos and A. Athienitis (2011). "Airflow assessment in cross-ventilated buildings with operable façade elements." Building and Environment 46(1): 266-279.

Kasim, N., S. Zaki, M. Ali, N. Ikegaya and A. Razak (2016). "Computational Study on the Influence of Different Opening Position on Wind-induced Natural Ventilation in Urban Building of Cubical Array." Procedia Engineering 169: 256-263.

Kasim, N., S. Zaki, A. Hagishima, M. Ali, M. Shirakashi, N. Arai and A. Razak (2014). "CFD Study of Cross Ventilation Performance of Different Buildings Layouts."

Katayama, T., J. Tsutsumi and A. Ishii (1992). "Full-scale measurements and wind tunnel tests on crossventilation." Journal of Wind Engineering and Industrial Aerodynamics 44(1-3): 2553-2562.

Kim, J., P. Moin and R. Moser (1987). "Turbulence statistics in fully developed channel flow at low Reynolds number." Journal of fluid mechanics 177: 133-166.

Kobayashi, T., K. Sagara, T. Yamanaka, H. Kotani, S. Takeda and M. Sandberg (2009). "Stream tube based analysis of problems in prediction of cross-ventilation rate." International Journal of Ventilation 7(4): 321-334.

Kurabuchi, T., M. Ohba, T. Goto, Y. Akamine, T. Endo and M. Kamata (2005). "Local Dynamic Similarity Concept as Applied to Evaluation of Discharge Coefficients of Cross-Ventilated Buildings-Part 1 Basic Idea and Underlying Wind Tunnel Tests; Part 2 Applicability of Local Dynamic Similarity Concept; Part 3 Simplified Method for Estimating Dynamic Pressure Tangential to Openings of Cross-Ventilated Buildings." International Journal of Ventilation 4(3): 285.

Lateb, M., R. Meroney, M. Yataghene, H. Fellouah, F. Saleh and M. Boufadel (2016). "On the use of numerical modelling for near-field pollutant dispersion in urban environments- A review."

Environmental Pollution 208: 271-283.

Launder, B. and D. Spalding (1974). The numerical computation of turbulent flows. Computer Methods in Applied Mechanics and Energy, 3, 269-289.

Mirzaei, P. A. and J. Carmeliet (2013). "Dynamical computational fluid dynamics modeling of the stochastic wind for application of urban studies." Building and Environment 70: 161-170.

Mirzaei, P. A. and F. Haghighat (2011). "Pollution removal effectiveness of the pedestrian ventilation system." Journal of Wind Engineering and Industrial Aerodynamics 99(1): 46-58.

Mochida, A., H. Yoshino, S. Miyauchi and T. Mitamura (2006). "Total analysis of cooling effects of crossventilation affected by microclimate around a building." Solar Energy 80(4): 371-382.

Mochida, A., H. Yoshino, T. Takeda, T. Kakegawa and S. Miyauchi (2005). "Methods for controlling airflow in and around a building under cross-ventilation to improve indoor thermal comfort." Journal of Wind Engineering and Industrial Aerodynamics 93(6): 437-449.

Mohamed, M. S. and J. C. LaRue (1990). "The decay power law in grid-generated turbulence." Journal of Fluid Mechanics 219: 195-214.

Murakami, S. (1991). "Wind tunnel test on velocity-pressure field of cross-ventilation with open windows." ASHRAE transactions 97: 525-538.

Ohba, M., T. Kurabuchi, Y. Fugo and T. Endo (2002). Local similarity model of cross-ventilation Part 2 Application. The 8th international conference on air distribution in rooms 'ROOMVENT.

Ohba, M., T. Kurabuchi, E. Tomoyuki, Y. Akamine, M. Kamata and A. Kurahashi (2004). "Local Dynamic Similarity Model of Cross-Ventilation Part 2-Application of Local Dynamic Similarity Model." International Journal of Ventilation 2(4): 383-394. 
Pope, S. B. (2001). Turbulent flows, IOP Publishing.

Prakash, D. and P. Ravikumar (2015). "Analysis of thermal comfort and indoor air flow characteristics for a residential building room under generalized window opening position at the adjacent walls."

International Journal of Sustainable Built Environment 4(1): 42-57.

Ramponi, R., A. Angelotti and B. Blocken (2014). "Energy saving potential of night ventilation: Sensitivity to pressure coefficients for different European climates." Applied Energy 123: 185-195.

Ramponi, R. and B. Blocken (2012). "CFD simulation of cross-ventilation for a generic isolated building: impact of computational parameters." Building and Environment 53: 34-48.

Ramponi, R. B., Blocken (2015). "CFD simulation of outdoor ventilation of generic urban configurations

with different urban densities and equal and unequal street widths." Building and Environment 92: 152166.

Razak, A. A., A. Hagishima, N. Ikegaya and J. Tanimoto (2013). "Analysis of airflow over building arrays for assessment of urban wind environment." Building and Environment 59: 56-65.

Rhie, C. M. and W. L. Chow (1983). "Numerical study of the turbulent flow past an airfoil with trailing edge separation." AIAA Journal 21(11): 1525-1532.

Richards, P. and R. Hoxey (1993). "Appropriate boundary conditions for computational wind engineering models using the $k-\epsilon$ turbulence model." Journal of wind engineering and industrial aerodynamics 46:

145-153.

Richards, P. and S. Norris (2011). "Appropriate boundary conditions for computational wind engineering models revisited." Journal of Wind Engineering and Industrial Aerodynamics 99(4): 257-266.

Rodi, W. (1997). "Comparison of LES and RANS calculations of the flow around bluff bodies." Journal of wind engineering and industrial aerodynamics 69: 55-75.

Sawachi, T., N. Ken-ichi, N. Kiyota, H. Seto, S. Nishizawa and Y. Ishikawa (2004). "Wind pressure and air flow in a full-scale building model under cross ventilation." International Journal of Ventilation 2(4): 343357.

Shih, T.-H., W. W. Liou, A. Shabbir, Z. Yang and J. Zhu (1995). "A new k- $\epsilon$ eddy viscosity model for high reynolds number turbulent flows." Computers \& Fluids 24(3): 227-238.

Shirzadi, M., P. Mirzaei and M. Naghashzadegan (2017). "On the cross ventilation for a generic building in unsheltered and sheltered conditions "16th International Conference on Sustainable Energy Technologies.

Sieminski, A. (2015). "International energy outlook." Energy Information Administration (EIA). Stavridou, A. D. and P. E. Prinos (2017). "Unsteady CFD Simulation in a Naturally Ventilated Room with a Localized Heat Source." Procedia Environmental Sciences 38: 322-330.

Tamura, Y. (2012). "Aerodynamic database for low-rise buildings." Global Center of Excellence Program, Tokyo Polytechnic University, Database.

Tamura, Y., T. Ohkuma, H. Kawai, Y. Uematsu and K. Kondo (2004). Revision of AlJ Recommendations for wind loads on buildings. Structures 2004: Building on the Past, Securing the Future: 1-10.

Tavoularis, S. and U. Karnik (1989). "Further experiments on the evolution of turbulent stresses and scales in uniformly sheared turbulence." Journal of Fluid Mechanics 204: 457-478.

Tominaga, Y. (2015). "Flow around a high-rise building using steady and unsteady RANS CFD: Effect of large-scale fluctuations on the velocity statistics." Journal of Wind Engineering and Industrial Aerodynamics 142: 93-103.

Tominaga, Y. and B. Blocken (2015). "Wind tunnel experiments on cross-ventilation flow of a generic building with contaminant dispersion in unsheltered and sheltered conditions." Building and Environment 92: 452-461. 
Tominaga, Y. and B. Blocken (2016). "Wind tunnel analysis of flow and dispersion in cross-ventilated isolated buildings: impact of opening positions." Journal of Wind Engineering and Industrial

Aerodynamics 155: 74-88.

Tominaga, Y., A. Mochida, R. Yoshie, H. Kataoka, T. Nozu, M. Yoshikawa and T. Shirasawa (2008). "AIJ guidelines for practical applications of CFD to pedestrian wind environment around buildings." Journal of wind engineering and industrial aerodynamics 96(10): 1749-1761.

Tong, Z., Y. Chen and A. Malkawi (2016). "Defining the Influence Region in neighborhood-scale CFD simulations for natural ventilation design." Applied Energy 182: 625-633.

van Hooff, T., B. Blocken and Y. Tominaga (2016). "On the accuracy of CFD simulations of crossventilation flows for a generic isolated building: comparison of RANS, LES and experiments." Building and Environment.

Walton, G. and W. Dols (2006). "CONTAM 2.1 Supplemental user guide and program documentation. 2006." Gaithersburg, MD: National Institute of Standards and Technology Google Scholar. Yakhot, V. and S. A. Orszag (1986). "Renormalization-group analysis of turbulence." Physical review letters 57(14): 1722.

Yang, F., Y. Gao, K. Zhong and Y. Kang (2016). "Impacts of cross-ventilation on the air quality in street canyons with different building arrangements." Building and Environment 104: 1-12.

Yang, T., N. Wright, D. Etheridge and A. Quinn (2006). "A comparison of CFD and full-scale measurements for analysis of natural ventilation." International Journal of Ventilation 4(4): 337-348. Younis, B. A. and Y. Zhou (2006). "Accounting for mean-flow periodicity in turbulence closures." Physics of Fluids (1994-present) 18(1): 018102.

Zaki, S. A., A. Hagishima and J. Tanimoto (2012). "Experimental study of wind-induced ventilation in urban building of cube arrays with various layouts." Journal of Wind Engineering and Industrial Aerodynamics 103: 31-40. 